\title{
DAS BILD VON POMPEJI IM UNTERRICHT IN DEN BÖHMISCHEN KRONLÄNDERN. DIE ZEIT DES HABSBURGISCHEN SCHULWESENS (1849-1918)
}

\author{
JANA KEPARTOVÁ
}

\begin{abstract}
The Image of Pompeii in Classes in the Countries of the Bohemian Crown.

The Time of Habsburgian Schooling (1849-1918)

Pompeii and its death was for a long time not a topic either in classes of classical languages nor in other subjects. History school books mostly limited themselves to the statement that Pompeii had been destructed during the reign of Titus; children could find out more about the fate of Pompeii in German and Czech reading-books. All these textbooks had for a long time no illustrations. The first pictures from Pompeii can be found in the history textbooks by Gindely. Some plans as well as pictures students found in art class schoolbooks and on the school corridor walls. They could use also some of the school compendiums which were in the students' school libraries.
\end{abstract}

Keywords: Pompeii; Greek schoolbooks; Latin schoolbooks; History text books; German reading-books; Czech reading-books; works for Art classes; Countries of the Bohemian Crown; Habsburgs; Austria

Wie bekannt, ist man auf die Ruinen von Pompeji zuallererst 1592 gestoßen. Dieser Fund wurde jedoch verkannt und die Stadt hat weitere zwei und halb Jahrhunderte unter der Asche und der Vesuvlava "geschlafen“. Von 1748 an spricht man vom Beginn der Ausgrabungen in Pompeji, um eine Dekade früher hat man in Herkulaneum zu graben begonnen. Nach mehr als einem weiteren Jahrhundert (seit 1860) kann man endlich von wissenschaftlichen Ausgrabungen sprechen, die untrennbar mit dem Namen von Giuseppe Fiorelli verbunden sind. Nun entsteht die Frage, wie Pompeji und die ganze Gegend im Golf von Neapel sich das Unglück des Jahres 79 n. Chr. in den Edukationsprozess der österreichischen Mittelschulen in der zweiten Hälfte des 19. Jh. und den ersten zwei Dekaden des 20. Jh. integriert hat, mit welchen Vorstellungen über das schreckliche Los der Gegend unter dem Vesuv die Knaben und Jünglinge ${ }^{1}$ die Mittelschule haben

1 Damalige Terminologie für die Lernenden der unteren und oberen Klassen. Vgl. Entwurf (1849); Mauthner (1918: 37) bemerkt jedoch, dass ab der Prima alle Gymnasiasten als „Studenten“ bezeichnet 
verlassen können, was sie in den Bildungsanstalten über Pompeji ${ }^{2}$ gelernt haben, und nicht zuletzt, inwieweit Pompeji als erkannter Grundstock unserer Kenntnis des alltäglichen Lebens genutzt wurde. Der Leitgedanke des Aufsatzes von Kepartová (2014) war die griechisch-römische Antike allgemein im gymnasialschulischen Unterricht des dritten Viertels des 19. Jh. als Folge des Beitrages von Svatoš (1994) über den Unterricht der klassischen Sprachen in demselben Zeitraum und Territorium. In der Fortsetzung wird das Thema der vorgelegten Studie einerseits auf das Bild von Pompeji eingeengt, andererseits auf die Zeitspanne von 1849-1918 ausgedehnt, d.h. nach der Exner-Bonitz Schulreform ${ }^{3}$ und vor dem Entstehen der Tschechoslowakischen Republik im Jahre 1918. ${ }^{4}$

Bei der Untersuchung wurde folgende Begrenzung gegeben: die untersuchten Lehrund Lesebücher wurden in den unteren und den höheren Gymnasien und anderen Mittelschulen des Gebietes der heutigen Tschechischen Republik benutzt, im deutschen wie im tschechischen Unterricht, die schulische sowie die außerschulische Pflichtlektüre eingeschlossen. Dies - natürlich neben der Lehrerauslegung ${ }^{5}$ und der privaten Lektüre ${ }^{6}$ - hat nämlich die Grundlage der Anschauung über die lebendige Alltagsantike geprägt, die sonst nur durch die trockene, auf die Grammatik ausgerichtete, Lateinlektüre erworben werden konnte. Die deutsch geschriebenen, geschichtlichen wie sprachlichen (für den Gegenstand Deutsch und Tschechisch) Unterrichtswerke wurden herangezogen, weil die Kinder und die Jugendlichen aus deutschen Lehrbüchern lange gelernt haben. Nachdem die Landessprache als Unterrichtssprache zugelassen worden war, ${ }^{7}$ hatten ja alle die Möglichkeit, in den Schülerbibliotheken (im Entwurf 1849: 42, § 55: Lehrmittelsammlungen, als wünschenswert, seit 1896 obligatorisch an jedem Gymnasium samt des Kataloges 8 vorhanden) nicht nur tschechische, sondern auch deutsche Werke, in denen über Pompeji entweder in der Belletristik (z.B. in der Schülerbibliothek in Brünn Marcus Charinus, der junge Christ in Pompeji von Alberti 1872) ${ }^{9}$ oder aber in den Kompendien und Publikationen über die römischen Realien geschrieben wurde, auszuleihen; in den Schülerbibliotheken finden wir Beweise dafür, und in dem Deutsch- und Tschechischunterricht

wurden (,in Österreich nennt man alle Gymnasiasten Studenten, wie man jeden Mann aus dem Volke adelt").

2 Unter dem vereinfachten Begriff Pompeji verstehe ich in dieser Abhandlung meist die ganze Gegend, die vom Vesuv vernichtet wurde, einschl. des damaligen königlichen Museums in Portici, das später nach Neapel umgesiedelt wurde, und einschl. des Museums an der Porta Marina in dem archäologischen Gebiet (1860-1980).

3 S. Entwurf (1849).

4 Es ist zwar wahr, dass die ersten Lehrwerke der neuen Tschechoslowakischen Republik in vieler Hinsicht auf die österreichischen zurückgegriffen haben, doch geht es hier um eine neue Periode in dem Schulwesen.

5 Die allerdings von manchen Absolventen sehr kritisch angesehen werden konnte, wie der deutsch-böhmische Philosoph und Schriftsteller Fritz Mauthner, ein Gymnasiast an dem piaristischen Gymnasium in Prag-Neustadt in den Jahren 1861-1866 und dann an dem Kleinseitner Gymnasium, anschaulich in seinen Erinnerungen schildert (Mauthner 1918: bes. Kap. V. und Kap. VII.).

6 Dass die Privatlektüre viel mächtiger war (und bis heute ist) beweist Mauthner (1918: 59-60), der seine ausserschulischen Aktivitäten in seinen Erinnerungen beschreibt: er spricht sogar von einer „Lesewut".

$7 \mathrm{Zu}$ dieser Frage sowie zur Frage des obligatorischen Deutschunterrichtes an tschechischen Mittelschulen zusammenfassend Petrbok (2007: 252-257) mit weiterführender Literatur.

8 Erlass des hohen k. k. Ministerium für Cultus und Unterricht vom 30. 12. 1896 und Entwurf (1849) für die Anlage der gedruckten Kataloge der Lehrerbibliotheken an Mittelschulen.

9 Zur Bewertung s. Moormann (2011: 172-173). 
in den Lehr- als auch in den Lesebüchern sind antike Themen mitunter auch enthalten. Die Frage, wie hoch das Prozent der tschechischen Gymnasiasten war, die imstande waren, deutsche Lesestücke wirklich zu verstehen, wird hier außeracht gelassen. Außer den Gegenständen Latein, Griechisch, Geschichte, Deutsch und Tschechisch wird auch der freie Zeichenunterricht herangezogen. Es muss noch gesagt werden, dass die Lehrund Lesebücher besonders der Geschichte, und der Sprachen sowie der Religionswissenschaft einen wesentlichen Einfluss auf die öffentliche Meinung nicht nur der zukünftigen Staatsbürger, sondern auch deren Eltern ausübten, deshalb wurden sie sowohl vom Staat als auch von der Kirche mit scharfem Blick verfolgt. Und dies auch dann, als (seit 1855) die Mittelschulbücher auch von Privaten herausgegeben werden durften. Alle in den Bildungsanstalten benutzten Lehrmittel mussten von dem Wiener Ministerium approbiert werden und bedurften auch der Zustimmung der Bischöfe. ${ }^{10}$ In demselben Jahr, 1855, hat der Staat ein Konkordat mit der Kirche abgeschlossen ${ }^{11}$ und erst seit 1867 kam es zur Säkularisation des Schulwesens, die aber keine wesentlichen Änderungen der Auslegung der Ereignisse aus dem Jahr 79 n. Chr. ${ }^{12}$ und auf das römische Alltagsleben mit sich brachte. Der Vesuvausbruch und die Zerstörung Pompejis als Folge der paganen Weltanschauung werden in der christlichen Kinderliteratur geschildert. ${ }^{13}$

Zuerst müssen jedoch ein paar Worte zu der Pompeji und Herkulaneum-Kenntnis in den böhmischen Kronländern im kurzen Umriss gesagt werden. Es war das mährische Olmütz, in dem die Intelligenz über das Ende von Herkulaneum zuerst (im J. 1748) lesen konnte, und dies darüber hinaus nicht auf Lateinisch, sondern (eine „revolutionäre“ Neuigkeit!) auf Deutsch. ${ }^{14}$ Die Habsburger haben aber schon 1795 die Leseräume in größeren Städten abgeschafft, und die Bücherausleihstellen verboten, weil sie schädlich geworden seien. ${ }^{15}$ Aber man konnte die Entwicklung doch nicht stoppen, und so bekam auch die Bevölkerung der böhmischen Länder langsam die Möglichkeit über die Ereignisse des Jahres 79 n. Chr. im Golf von Neapel und ihre Folgen in den Zeitschriften zu lesen, und dies nun nicht nur auf Deutsch, sondern mit der nationalen Wiedergeburt immer öfters auch auf Tschechisch. ${ }^{16}$ Und nicht nur in den Zeitschriften, sondern mit der Zeit auch in Büchern, wenn es sich auch oft um Übersetzungen handelte (so z.B. aus dem Französischen ${ }^{17}$ oder aus dem Deutschen ${ }^{18}$ ). Seit der Veröffentlichung Milota Zdirad Poláks Cesta

10 Mikolášková (2012: 33). Seit 1850 wurden in der Zeitschrift für österreichische Gymnasien diese approbierten Schulmedien vorgestellt und ihre Rezensionen veröffentlicht.

11 Šafránek (1918: 74).

12 Ich lasse nun beiseite die Frage des genauen Datums, das neuerlich vom 24. August auf den 24. Oktober des Jahres 79 verlegt wird. Borgongino, Stefani (2001-2002); Stefani, Borgongino (2007).

13 Z.B. Nieritz (1865).

14 In den Monathlichen Auszügen alt / und neuer Gelehrter Sachen, hat die Societas incognitorum im zweiten Band 1748 auf nur 3 Seiten (919-921) im Einvernehmen mit dem Vorhaben, über die neuesten wissenschaftlichen Entdeckungen u. ä. zu referieren, einen kurzen Bericht aus Paris über die herkulanensischen Funde übernommen. Die Zeitschrift ist bald eingegangen.

15 Šafránek (1918: 215); Mikolášková (2012: 19).

16 Pacovský (1816: 393-394). Die Zeitschrift Prvotiny sollte in erster Reihe das Niveau der tschechischen Literatur heben, es wurden hier aber auch erzieherische Beiträge publiziert. Allerding sollte die Übersetzung ja u.a. beweisen, dass das Tschechische imstande ist, auch wissenschaftliche Texte widerzugeben.

17 Lemercier (1847); übersetzt von K. W. Püner.

18 Nieritz (1865); übersetzt von J. Pečírka. Das deutsche Original: Nieritz (1850). Nieritz’s Werke wurden tüchtig in den Schulen gelesen, wie sich Machar (1984: 47) erinnert. 
do Itálie (Reise nach Italien, 1862, zuvor als Zeitschriftenfolge in Dobroslav, 1820-1822)19 beginnt eine Reihe von Texten über Pompeji und Herkulaneum, so dass die unglücklichen Städte so bekannt wurden, dass der berühmte Historiker und Gymnasiallehrer in Tábor M. Kolář Mitte der sechziger Jahre schon darauf bauen konnte, dass die Leser es verstehen, wenn er Sezimovo Ústí als „das böhmische Herculaneum und Pompeji“ nannte ${ }^{20}$ oder als er eine kurze Satire über den Vesuv veröffentlichte, ${ }^{21}$ bis endlich auch die ersten originalen monographischen Schilderungen des Lebens in Pompeji auf Tschechisch von zwei Lehrern herausgegeben wurden: zuerst erschien ein Jahr nach dem 1800 . Jahrestag der Vesuveruption ein Büchlein aus der Feder des Schriftstellers, Reisendes und Mittelschullehrers der modernen Sprachen und des Tschechischen und der Geographie, Josef Wünsch, ${ }^{22}$ und dann fast ein viertel Jahrhundert später ein (wieder ziemlich dünnes) Buch von dem klassischen Philologen und Gymnasiallehrer Josef Pražák. ${ }^{23}$ Das ist jedoch schon die Zeit, als auch die tschechischen Lehrer und Touristen öfters die Ruinen der Stadt besuchten; die österreichischen Schulmänner haben die Gelegenheit bekommen, ein halbjähriges Reisestipendium von dem Wiener Ministerium für Cultus und Unterricht zu erwerben, um die antike Kultur aus eigener Erfahrung kennenzulernen (1893-1914). Und noch im letzten Jahre des ersten Weltkrieges erscheint eine Satire mit dem Titel „Das böhmische Pompeji“. ${ }^{24}$ Die deutsche Produktion war natürlich viel reicher. Man konnte also damit rechnen, dass nicht nur das Besitzbürgertum und das Bildungsbürgertum, sondern auch die durchschnittlich gebildete Bevölkerung Kenntnis von den Ereignissen am Golf von Neapel hatte. ${ }^{25}$

Wie sah es aber mit der Kenntnis aus, die die Schüler in den Lehranstalten erworben haben, darauf wird jetzt näher eingegangen. In Deutschland hat schon 1842 der Professor am Gymnasium zu Bruchsal Ch. Theophil Schuch verlangt, dass die Studenten mehr das Privatleben der Römer kennenlernen sollten. Dies impliziert das Kennenlernen des pompejanischen Materials: „Die Alterthümer, welche eine geistige Statistik des antiken Lebens sind und im weitesten Sinne das alterthümliche Leben in allen Richtungen der Nationalität zum Gegenstande haben, und somit auch die politische Geschichte, Mythologie, Literatur u. dgl. umfassen; im engern Sinne aber die eigenthümlichen Erscheinungen des Lebens in seiner charakteristischen fortschreitenden Entwicklung, auf allen Stufen derselben, in den mannigfaltigsten Lebensverhältnissen - diese Alterthümer dürfen nicht mehr wie früher als bloßer Anhang der Geschichte beigesellt werden. Bloß geographische, geschichtliche und allgemein-statistische Kenntnisse von den alten Völkern und Staaten genügen uns nicht mehr: man will auch etwas Näheres von ihrem Erwerbfleiße, ihren Künsten, ihren Spielen, Gebräuchen und Sitten, ihrem Luxus, ihrer ästhetischen

19 S. Kepartová (2000: 153-159).

20 [Kolář] (1865); Honl (1967: 22) führt folgende Gründe dafür an: Sezimovo Ústí (Alttabor) steht auf den Ruinen einer älteren Stadt, die während der Hussitenkriege vernichtet wurde. Wegen der Bedeutung der damaligen Ausgrabungen hat also Martin Kolář diese Stadt als das böhmische Herkulaneum bezeichnet.

21 [Kolář] (1866).

22 Wünsch (1880). Dazu die Monographie J. Kepartová, Die antike Welt des Lehrers Josef Wünsch, in Vorbereitung.

23 Pražák (1903). S. Kepartová (2001).

24 Anonym (1918).

25 Kepartová (2007a: passim). 
und wissenschaftlichen Bildung kennen lernen. " ${ }^{26}$ Nicht, dass es allgemeine Lexika zum Privatleben mitunter auch für den Schulgebrauch nicht gegeben hätte, die Wiener Schulbuchhandlung hat z.B. in den Jahren 1800-1805 ein fünfbändiges Werk herausgegeben, ${ }^{27}$ das noch nach fast einem Jahrhundert immer wieder in neuen Auflagen erschien, Pompeji kommt jedoch sehr kurz vor ${ }^{28}$ und die Lexika sind darüber hinaus unbebildert. Zu der Zeit, in der Schuch sein Verlangen nach mehr Privatleben im Unterricht äußerte, gab es für die Jugend schon auch Romane, die auf archäologischen Entdeckungen basierten. Das Material aus Pompeji hat z.B. W. A. Becker sehr gut in seiner Belletristik benutzt, ${ }^{29}$ auch wenn er die Erzählung nicht nach Pompeji verlegt. Es geht hier um die künstlerische Schilderung des Schicksals von Cornelius Gallus, dem ersten Präfekten Ägyptens, als Freund / Feind des ersten Prinzeps August. Doch nach jedem Kapitel bekommt der Leser eine detaillierte Auslegung von bezüglichen Alltagsbeschreibungen. Und eben hier benutzt Becker die neuesten Erkenntnisse über die pompejanischen Funde. Daher konnte das Werk als Handbuch des römischen Lebens dienen. ${ }^{30}$

Man könnte erwarten, dass das Natürlichste für die Auslegung des antiken Lebens die Stunden der klassischen Sprachen sind.

\section{Lateinlehrwerke für die österreichischen Mittelschulen}

Lateinische Grammatik-Bücher. In den Grammatiken haben die Schüler sehr lange nur an den einzelnen (oft erfundenen) Sätzen gelernt. Eine Methode, die zwar kritisiert, sehr lange jedoch benutzt wurde. Diese Praxis haben viele bemängelt, eigentlich seit langem. ${ }^{31}$ Aus dem Kanon der römischen Autoren, zu dem Plinius der Jüngere ${ }^{32}$ - Augenzeuge und Autor von zwei Briefen über den Vesuvausbruch an den Historiker Tacitus - in dieser Zeit nicht angehörte, wurden einzelne Gedanken nach der bisher gelehrten Grammatik umgeformt, präpariert. Bald erschienen deshalb unterschiedliche Kompendien, die an die studierende Jugend ausgerichtet waren. ${ }^{33}$ Es fehlten lange auch die Illustrationen hier wäre ja ein Spielraum für die Widergabe des pompejanischen Materials gewesen. Man hat schon bald das Fehlen der Illustrationen in den Schulbüchern gespürt, es gab

26 Schuch (1842: VIII).

27 Funke et al. (1800-1805).

28 Funke et al. (1800-1805: IV, 623 [s.v. „Pompeji“; ein Absatz] und V, 957-958 [s.v. „Vesuv“]).

29 Becker (1838-1840).

$30 \mathrm{Zu}$ dem Kontext mit Bulwers Roman s. Harrisson (2011: 82-84) und Kepartová (2016).

31 So Mauthner (1918: 58): „Ich drückte die Bank und hatte die Hoffnung aufgegeben, auf diesem Gymnasium jemals geistige Fortschritte zu machen. Die Einführung in das antike Kulturleben blieb aus; und was ich für den Schulbedarf brauchte, das flog bei dem ewigen Wiederkäuen des armseligen Stoffs einem von selber an, auch wenn man während der Schulstunde Goethe las oder schwer gereimte Sonette schmiedete. Man brauchte nur dann und wann hinzuhören. " $\mathrm{Zu}$ den deutschen Erfahrungen s. Fritsch (1976: 116-169, bes. 131-138).

32 Auch keine anderen griechischen und römischen Autoren, die die Katastrophe kannten, gehörten zu dem Kanon der antiken Literatur; allerdings hat keiner von ihnen mehr als Plinius berichtet.

33 Es ist bezeichnend, dass meistens zuerst die Compendien für Rom herausgegeben wurden und diejenigen für Griechenland erst dann folgten - es hing natürlich mit dem Schulplan zusammen. So z.B. zum Gebrauch für Gymnasien und Schulen Bojesen, Hoffa (1841), Schuch (1842) und viele andere. 
jedoch keinen Willen für die Begleitung des Bildes zu den Schultexten: die gelehrten Werke waren schon seit der Spätantike unbebildert und die Sprachübungsbücher waren als solche von der neuhumanistischen Gesellschaft angenommen. Das Fehlen der Bilder wurde also (wenn auch sporadisch) separat ersetzt. Hohler (1822) z.B. will damit die Jugend anregen, die dreidimensionalen Originale oder aber ihre Kopien in den österreichischen Sammlungen aufzusuchen. ${ }^{34}$ Doch um die Mitte des 19. Jh. wurden (mitunter auch wegen der vermissten textbezogenen Bilder und der oft beschriebenen trockenen Drillmethode) zunehmend zur Belebung des Unterrichtes Bildbände und anderes Anschauungsmaterial (bes. Wandbilder und Wandtafeln) herausgegeben. Von 1860 an erschienen illustrierte Geschichtslehrbücher (s. unten), das erste bebilderte deutsche lateinische Übungsbuch stammt von Ludwig Gurlitt, das erst 1897 für die Sexta erschien. Es war mit freien Zeichnungen illustriert - und von den Gebildeten abgelehnt. ${ }^{35}$ Von da $\mathrm{ab}$ durften die Lateinbücher nur mit Originalen oder Rekonstruktionen der Originale ausgeschmückt werden, wenn überhaupt. Es ging also eher um die traditionsgebundenen Vorstellungen als um die technischen Möglichkeiten. Seit der Erfindung der Autotypie Anfang der achtziger Jahre des 19. Jh. wären ja die Bilder in Schulbüchern leichter möglich gewesen. In Deutschland, woher die Anregungen auch für die österreichischen Schulbuchautoren herkamen, hat man erst in den preußischen Richtlinien aus dem Jahre 1925 die Abbildungen, die als "Skizzen“ bezeichnet werden mussten, zugelassen. ${ }^{36}$ Auch in den tschechischen Latein- und Griechisch-Grammatikbüchern blieben in dem untersuchten Zeitraum Illustrationen aus.

Konnte man also die Grammatik-Bücher nicht mit Illustrationen aus dem Leben schmücken, hat man schon vor der Reform der österreichischen Gymnasien Hilfsbücher des römischen Alltagslebens herausgegeben, denn ohne ein Grundwissen davon hätten ja die Kinder kaum die Texte verstehen können. Dies war der eigentliche Zweck solcher Schulhilfebücher. Und hier konnte man kaum ohne textbezogene Bilder aus Pompeji auskommen. ${ }^{37}$

34 Hohler (1822: IV-VI). „Viele höchst seltene und interessante Exemlare sind theils in dem k. k. Münzund Antiken-Cabinette und in der k. k. Hof-Bibliothek zu Wien, theils in den verschiedenen Sammlungen an anderen Orten des Österreichischen Kaiserstaates öffentlich aufbewahret ... dem Studium derselben einen höheren Reitz und eine größere Lebendigkeit zu geben. Diese Abbildungen sind mit Rücksicht auf das System des neu eingeführten Lehrbuches der Römischen Alterthümer für die Grammatical-Classen in den k. k. Gymnasien (Wien, im Verlage der k. k. Schulbücher-Verschleiß-Administration, ergänzt von J. K.) eingeordnet. Der Inhalt des beygefügten Textes beschrängt sich auf eine kurze Erläuterung der Abbildungen; die ausführlichere Erklärung der abgebildeten Gegenstände findet der Leser in dem angezeigten Lehrbuche." So ein Buch konnte nicht an Pompeji vorbeigehen, so in der Tafel IX „Römische Bauart“ (Hohler 1822: 32-33) lesen und sehen wir das Innere des Hofraumes nach Hamilton. Da der Verf. nicht voraussetzte, dass die Leser über das Schicksal Pompejis wissen, hat er es erläutert: „Pompeji, Herkulanum und Stabiä waren drey alte Städte nicht weit von Neapel, die im J. 79 nach Chr. G. bey einem Ausbruche des Vesuvs versanken und mit Lava überschüttet wurden. Seit dem J. 1783 (sic, J. K.) werden die Nachgrabungen in diesen Städten mit dem glücklichsten Erfolge betrieben." Auf der nächsten Taf. gibt Hohler (1822: 34-35) ein Hofraum mit einem Säulengange nach Voyage pittoreque de Naples wider. Als Grammatikal-Klassen wurden die ersten drei Jahrgänge bezeichnet.

35 Rothenburg (2009: 186-188).

36 Rothenburg (2009: 187-189).

37 Die Illustrationen bringen z.B. Stefan (1868); Guhl, Koner (1860 [317 Holzschnitten]; 1861 [211 Holzschnitte]). Diese Verf. haben nicht nur an „die Lernenden, sondern auch an das grössere gebildete Publikum“ gedacht. Pompeji ist natürlich sehr viel vertreten. 
Lateinische Lesebücher. Pompejanisches Material eignet sich ausgezeichnet als Beispiel für verschiedene Seiten des sowohl öffentlichen als auch privaten Lebens zur Erklärung der Lektüre unterschiedlicher römischer Autoren, auch wenn sie nicht gerade über die unglückliche Stadt referieren. Zahlreiche basieren auf den Funden aus der Gegend unter dem Vesuv, ohne dass man es in dem Schulbuch expressis verbis notiert.

In den ersten Klassen des Untergymnasiums hat man natürlich Lesestoffe zu den Autoren gewählt, an denen die Schüler die Grammatik übten. ${ }^{38}$ Passagen aus Plinius und damit die Beschreibungen des Vesuvausbruches waren auch in den Lesebüchern nicht vorhanden. Die Verbindung mit anderen Unterrichtgegenständen, wie mit der Geschichte, hat ja auch in der Sekunda nicht geholfen, denn dort, wie wir noch zu hören bekommen, waren andere Prioritäten gesetzt. Auch in der Quinta und später noch in dem ersten Semester der Sexta, wenn die Studenten wieder mal über die Antike gelernt haben, hätten die Lernenden die Chance gehabt, über das alltägliche Leben nach dem pompejanischen Material zu erfahren.

„Die sittlich bildenden Elemente der Lektüre“ der Klassiker werden in dem Entwurf (1849: 102) betont. Dabei werden „tüchtige Schulausgaben“ der antiken Autoren empfohlen, besonders jedoch wegen stilistischer, synonymischer u. ä. Bemerkungen (Entwurf 1849: 112). Gaius Plinius der Jüngere hat lange nicht seinen festen Platz im Unterricht der lateinischen Sprache gehabt. In den Lehrplan wurde Plinius erst im J. 1911 eingereiht, wie wir von Ladislav Brtnický erfahren..$^{39}$ Es war der Gymnasiallehrer Josef Sedláček, einer der drei Autoren des größten lateinisch-tschechischen Wörterbuches, der sich dieser Aufgabe annahm und Plinius' Briefe für den Schulgebrauch vorbereitete. ${ }^{40}$ Damit haben die Schulkinder die detaillierte Beschreibung der Ereignisse kennengelernt. Die Lehrer hatten jedoch schon früher die Möglichkeit, die tschechische Übersetzung von den Pliniusbriefen nach der deutschen kritischen Edition und den deutschen Kommentaren, und zwar in dem Jahresbericht des Gymnasiums in Klattau, zu lesen. ${ }^{41}$ Die Jahresberichte der Mittelschulen waren jedoch den Lehrenden, nicht den Lernenden bestimmt.

\section{Geschichts-Lehrwerke für die österreichischen Mittelschulen}

Deutsche Lehrbücher. ${ }^{42}$ Wenn es in den Lateinstunden kaum Spielraum für die Auslegung von Themen, die nicht gerade in den Grammatikbüchern behandelt wurden, gab, ist es anzunehmen, dass das römische Privatleben den Geschichtsstunden überlassen wurde. Es soll hier gesagt werden, dass die Habsburger auf die Geschichtslehrbücher der deutschen Autoren zurückgegriffen haben; nur natürlich in der Oktava, wo man über die vaterländische Geschichte Österreichs unterrichtet hat, schuf man eigene, auf das habsburgische Haus ausgerichtete Schulbücher.

38 So z.B. in Böhmen gebrauchtes Lesebuch von Schinnagl (1853).

39 Brtnický (1912: 6-31).

40 Sedláček (1911).

41 Čapek (1910).

42 Allgemein zu den deutschen Geschichtslehrbüchern s. Jacobmeyer (2011). 
Zuerst sollten wir jedoch das Ziel des Geschichtsunterrichtes an den Unter- und Obergymnasien vorstellen: Während am Untergymnasium die „Uebersichtliche Kenntnis der Erdoberfläche nach ihren natürlichen und politischen Eintheilungen. Uebersicht der wichtigsten Personen und Begebenheiten aus der Völkergeschichte, namentlich aus der Geschichte Oesterreichs, und Kenntnis ihres chronologischen Zusammenhanges" verlangt wurde, ${ }^{43}$ wurden an dem Obergymnasium schon höhere Ansprüche gestellt: „Uebersicht über die Hauptbegebenheiten der Weltgeschichte in ihrem pragmatischen Zusammenhange; genauere Kenntnis der geschichtlichen Entwicklung der Griechen, Römer und des Vaterlandes. Ein sicheres Wissen der hiezu nöthigen geographischen Verhältnisse hat damit in Verbindung zu stehen. "44 In der Praxis hat sich jedoch gezeigt, dass für die Auslegung des Altertumes, das gründlich gelehrt werden sollte, ein Jahr nicht ausreicht, und so wurde die Alte Geschichte auch noch im ersten Semester der Sexta eingesetzt. Dies ist nachweisbar schon im Schuljahre 1854-1855 in Olmütz. ${ }^{45}$

Bei den meisten hier zitierten Werken handelt es sich um mehrbändige Schulbücher, die oft nach der Geschichtsgliederung nacheinander folgten. In dem vorliegenden Beitrag berücksichtige ich natürlich immer nur den Band, der der Alten Geschichte (einschl. Rom) gewidmet ist. Sollte ich ein konkretes Werk als Beispiel für die unteren Gymnasien nennen, würde ich zum Grundriss (zuerst erschienen im J. 1834) von dem kölnischen Gymnasiallehrer Wilhelm Pütz greifen (allerdings wurden die Unterrichtsmaterialien meist von den Lehrern verfasst), dem Autor, der auch für die Obergymnasien ein Schulbuch herausgab und dessen Werk sowohl von den Schulbehörden als auch von den Lehrenden anerkannt war. Bildungsanstalten, die nach seinem Schulbuch in der Sekunda unterrichtet haben, sind meist auch in der Quinta und Sexta bei ihm geblieben. In dem Jahresbericht aus Pilsen 1857 lesen wir, dass hier nach seinem Grundriss ,für die mittleren Klassen und für höhere Bürgerschulen" unterrichtet wurde, der gerade in die österreichischen Gymnasien und Bürgerschulen Eingang gefunden hatte. ${ }^{46}$ Pütz’s Werk ist jedoch sehr viel auf die politische Geschichte orientiert und nützt also das pompejanische

43 Dies hieß in der Sekunda in dem Gegenstand Geographie und Geschichte als Einheit bei wöchentlich 3 Stunden „Alte Geschichte bis 476 n. Chr. Die Geschichte des jüdischen Volkes mit der Geographie Palästina's bleibt dem Religionslehrer überlassen. Der Geschichte eines jeden auftretenden Volkes wird die Geographie des Landes vorausgeschickt, auf Grundlage der in der I. Klasse bereits gelernten allgemeinen Umrisse" (Entwurf 1849: 31). An Volksschulen sollten die Kinder nur eine Einleitung in die Geschichte bekommen. Nach Grube (1852: XI-XII) kann jedoch der Geschichtsunterricht in seinen Anfängen nichts Anderes als "Geschichten aus der Geschichte" sein. Er spricht von den 9-12jährigen Kindern (d.h. Schüler des Untergymnasiums) und mahnt, dass in der Propedäutik dazu am besten die Biographien bedeutender - den Kindern nahen - Persöhnlichkeiten „aus Fleisch und Knochen" passen (ohne jedoch in das andere Extrem zu fallen), und zwar nur über die Persönlichkeiten ohne Kontext. Daraus kann man jedoch schliessen, dass in den Lehrbüchern kein Platz für die Schilderung Pompejis Untergang Eingang finden konnte. Seine Auslegungen des ersten Teiles enden mit Antonius und Octavianus, es folgt eine kurze Übersicht über die Kultur der Römer und das Christentum.

44 In der Quinta hieß es bei wöchentlich 4 Stunden „die Alte Geschichte bis zur Völkerwanderung. Im 1. Semester bildet die griechische Geschichte, im 2. die römische den Hauptstamm der Geschichte; mit ihr sind zugleich die Alterthümer, namentlich die Staatsalterthümer zu verbinden, und die wesentlichen Punkte über die Entwicklung dieser Völker in Religion, Kunst und Literatur“" (Entwurf 1849: 32).

45 Jahres-Bericht (1855: 33).

46 Jahresbericht (1857: 15). Diese Ausgabe war im Vergleich mit dem anderen Lehrbuch von Pütz billiger, wie man im Entwurf (1849: 159) bemerkt. Die 6. Aufl. ist 1850 erschienen. 
Material nur in margine - wenn er über die Geographie Italiens berichtet und die Städte Kampaniens nennt, bemerkt er karg (Pütz 1850: 90): „Herculanum und Pompeji (verschüttet 79. n. Chr., im 18. Jh. wieder aufgefunden)“ und diese Information wiederholt er beim Kaiser Titus (Pütz 1850: 122), dem er jedoch nur einen ganz kurzen Absatz schenkt. Nun lag es an dem Lehrer, wieviel er den Kindern davon erzählen wollte.

Auch in den oberen Klassen des Gymnasiums war lange das sehr erfolgreiche Geschichtslehrbuch von Wilhelm Pütz in Gebrauch, dessen erste Auflage im Jahre $1833^{47}$ herausgegeben wurde und die vierte aus dem Jahre 1847 für die 5. Gymnasialklasse im Entwurf (1849: 159) als empfehlenswertes Schulbuch galt. Wie die meisten Geschichtsschulbücher für die Obergymnasien, so begrenzt sich auch Pütz's Werk wieder nur auf die Konstatierung, dass während der Regierung des Kaisers Titus der Vesuv ausgebrochen ist und die drei Städte samt der Umgebung total vernichtet hat. Besser sieht es auch nicht im Gindelys Schulbuche für die tschechischen Obergymnasien aus, dem ersten Buch für die Gymnasien mit tschechischer (in damaliger Terminologie böhmischer) ${ }^{48}$ Unterrichtssprache. ${ }^{49}$ Auch Gindely, Historiker sowie Mittel- und Hochschullehrer im tschechisch sprechenden Raum (Prag, Olmütz) ist sehr kurz: Die Flavier behandelt er auf kaum zwei Seiten, der Vesuvausbruch findet sich auch hier nur in einem Satz wider.

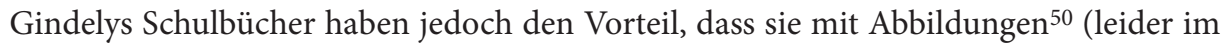
Anhang und kaum textbezogen) begleitet werden, darunter auch mit den Bildern aus Pompeji: die befestigte Stadtmauer (Fig. IV), das Herkulaner Tor (Fig. V), das Innere des Hauses (Fig. VIII, auch wenn es nicht als pompejanisches Haus bezeichnet wird), die pompejanischen Wandmalereien (Fig. IX), und viele Hausgegenstände hätte man natürlich ohne Pompejikenntnis gar nicht darstellen können. Gindelys Geschichtsbücher wurden immer wieder herausgegeben und haben die Geschichtsproduktion der Schulbücher sehr geprägt; sie wurden auch ins Tschechische übersetzt.

Tschechische Lehrbücher. Die ersten tschechischen Geschichtslehrbücher sind Übersetzungen aus dem Deutschen. Zu den verbreitetsten gehören die oben erwähnten Lehrbücher von Anton Gindely. Seine Schulbücher wurden von verschiedenen Tschechen übersetzt und bearbeitet, so von Josef Erben, ${ }^{51}$ Josef Jireček, der nur Erbens Übersetzung verbesserte, ${ }^{52}$ Matěj Kovář, dessen Ausgabe nur geringfügig von der des Jireček abweicht, ${ }^{53}$ Jan J. Řehák. ${ }^{54}$ Erst später wurden auch andere tschechische Lehrbücher abgefasst: Sobek (1900: 126) weist darauf hin, dass wir aus Pompeji eine perfekte Ansicht

47 Pütz (1833). Der Band über das Altertum wurde zweiundzwanzigmal herausgegeben und in mehrere Sprachen übersetzt.

48 In der damaligen Zeit hat man auch die Sprache als böhmisch bezeichnet; die etwas komplizierte Geschichte von den Begriffen tschechisch und böhmisch erläutert auf Deutsch sehr anschaulich Berger (2007).

49 Das früheste Exemplar, das ich anschauen konnte, stammt aus dem Jahre 1868 und stellt die zweite, verbesserte Auflage dar (Gindely 1868).

50 Der Regierungsrat Langl (1909: 18) bemerkt, dass sein Kollege im Amt, der Realschulelehrer Hanak, zum ersten Mal einem Geschichtsbuche kunstgeschichtliche Abbildungen beigefügt hat; alle früheren waren Zeichnungen meist nach antiken Skulpturen.

51 Gindely, Erben (1872).

52 Gindely, Jireček (1877).

53 Gindely, Kováŕ (1877).

54 Gindely, Řehák (1884). 
des römischen Lebens in allen seinen Details gewinnen können; Kameníček, Dvořák (1902: 213) sprechen von Pompeji mit Verweis auf „Langl Nr. 26“ (Langl 1872a-1872b; s. unten). Eins haben jedoch alle gemeinsam: sie sind von Gindely geprägt und Pompeji kommt kaum zu Wort.

Für den Schulgebrauch, aber auch für die breitere Öffentlichkeit hat im Jahre 1876 der Gymnasiallehrer František Velišský sein Buch Život Řekův a Římanův (Das Leben der Griechen und Römer) in Prag herausgegeben, ${ }^{55}$ das nicht ohne Heranziehen von Pompeji vorstellbar ist. Die Stadt kannte der Verfasser aus eigener Erfahrung und in seinem Unterricht hat er seine Schüler zum Reisen ermahnt ${ }^{56}$ - sein Buch haben viele gelesen, wie die Worte von dem zukünftigen berühmten Übersetzer antiker Autoren Otmar Vaňorný ${ }^{57}$ belegen: er schreibt, die Kommilitonen hätten an dem Obergymnasium in Rychnov nad Kněžnou (Reichenau an der Kniezna) Velišskýs Buch nach einzelnen Heften abonniert.

Aus den Geschichtsschulbüchern konnten also die Kinder und Jugentlichen kaum etwas Näheres über das Schicksal der vom Vesuv verschütteten Städte erfahren, sei es denn dass der Lehrer selbst in der Sache bewandert war und ihnen die Auslegung der römischen Geschichte mit seinen Erzählungen über die Naturkatastrophe etwas belebte. Die archäologischen Funde am Golf von Neapel fanden ihren Weg in die österreichischen Mittelschulen zuerst für die Lehrenden, ihnen standen einige Hilfsmaterialien zur Verfügung. ${ }^{58}$ Es ist natürlich schwer zu verfolgen, inwieweit das Alltagsleben nach den Ausgrabungen in der Realität in den Unterricht miteinbezogen wurde oder der begrenzten Zeit des Unterrichtes wegen überhaupt miteinbezogen werden konnte. Wie wir jedoch alle wissen, ist es der Lehrer in der Bildungsanstalt, der das Interesse wecken oder aber töten kann.

\section{Sprachlesewerke für die österreichischen Mittelschulen ${ }^{59}$}

Deutsche Lesebücher. Mit der Einführung des Gegenstandes Deutsch und Tschechisch an den österreichischen Mittelschulen eröffneten sich den Lernenden neue Möglichkeiten, wie sie ihr Wissen in Geschichte (aber nicht nur in diesem Fach) vertiefen

55 Velišský (1876). Mit dem eigenen Namen hieß er Lustig.

56 Stejskal (1913: 229): „... a nám studentům poutavě o těchto klassických zemích vypravoval a pobádal nás, abychom tyto klassické končiny navštěvovali“ [... und uns Studenten spannend über diese klassischen Länder erzählte und mahnte uns, diese klassischen Gegenden zu besuchen].

57 In Novotný (1936: 4).

58 Z.B. Klinghardt (1896; 1897). Der Aufsatz wird zwar auch von Kubik (1900: 1) gelobt, ist aber sehr auf Deutschland und die Denkmäler von Altenburg und auf die Untertertia (heutige 8. Klasse) ausgerichtet. Das ist jedoch leicht zu tun, wie Klinghardt (1896: 4) am Beispiel der Gegenüberstellung der Kultur der Römer und der Germanen vorschlägt. Hierbei zieht er auch das römische Pompeji als Beispiel städtischen Lebens heran und führt an: „wie in Pompeji, so sah es im ganzen und großen in den Römerstädten Deutschlands aus“. Doch kann der tschechische Lehrer, der auf keine von den Römern gegründete Stadt bei uns hinweisen kann, davon nur eine Inspiration für den Geographieund Geschichtsunterricht Europas gewinnen. Klinghardt (1896: 5-13) führt seine Schüler im Geiste durch Pompeji, und macht viele Beschreibungen und Erklärungen. In der Fortsetzung fügt Klinghardt (1897) Beispiele von Bauten in Deutschland (vom Mittelalter bis in das 19. Jh.) an.

$59 \mathrm{Zu}$ den deutschen sowie tschechischen Lesebüchern s. Petrbok (2007) mit weiterer Literatur. 
konnten. Man sollte ja die Jungen nicht nur zum Sprechen, sondern auch zum Lesen und dies nicht nur von Konversationstexten, sondern auch von der hohen Literatur in der entsprechenden Sprache führen. Dazu wurden sehr bald nach dem Entwurf (1849) deutsche und tschechische Lesebücher geschaffen, die zwar in erster Linie die ästhetische Wahrnehmung der Literatur bei den Lernenden und das literarische Interesse entdecken sollten und bis heute auch sollen, und erst in zweiter Linie didaktisch und moralisch erziehen sollten, ${ }^{60}$ aber - wie es im Entwurf (1849: 127) wortlautlich heißt: „Seinem Inhalte nach ... muss [ein Lesebuch, J. K.] dazu dienen, den in andern Unterrichtszweigen, namentlich in Geschichte, Naturgeschichte und Geographie dargebotenen Lehrstoff zu beleben." Die schriftlichen Aufsätze in Deutsch sollten gerade in der Sekunda, wenn der Geschichtsunterricht beginnt, vor allem über die historischen Themen verfasst werden (Entwurf 1849: 132). Schriftliche Aufsätze am Obergymnasium hatten schon höhere Ziele - die Jugentlichen sollten der „steigenden Bildung“, entsprechend qualitativ andere sein (Entwurf 1949: 134). Dabei spielt wieder die Geschichte eine wichtige Rolle, aber selbstverständlich auch „die Lektüre der griechischen und römischen Klassiker und die Beschäftigung mit der deutschen Literatur" sollten nicht zu kurz kommen. In dem Entwurf (1849: 134) finden die Lehrer ganz konkrete Themen. Pompeji befindet sich jedoch nicht darunter. Obwohl diese Anthologien das Bild der Vergangenheit nicht schufen und nicht schaffen sollten, konnten sie den Kindern doch helfen, das Geschehene, das in der Zeit vergangene, sich besser vorstellen zu können und es zu begreifen.

Die deutschen Lesebücher haben eine längere Tradition als die tschechischen und den tschechischen Herausgebern waren sie oft Vorbild. ${ }^{61}$ Zuerst entstanden Anthologien deutscher Schriftsteller für die Mittelschulen mit der deutschen Unterrichtssprache, erst seit der zweiten Hälfte der sechziger Jahre des 19. Jh. diejenigen für die Mittelschulen mit böhmischer/tschechischer Unterrichtssprache, für die ja das Deutsche zum obligatorischen Gegenstand wurde.

Einer der Mitarbeiter des Entwurfes (1849), Josef Mozart, hat nur ein Jahr nach der Bekanntmachung des Dokumentes begonnen, deutsche Lesebücher sowohl für die unteren, als auch für die oberen Gymnasialklassen herauszugeben; sie wurden dann wiederholt (u.a. auch umgearbeitet) herausgegeben. ${ }^{62}$ Es versteht sich, dass sie im Einklang mit dem Entwurf entstanden. Aber auch alle nachkommenden Anthologien von anderen Autoren mussten sich an den Richtlinien des Entwurfes (1849) halten. Doch wurde der Komplex der Mozartischen Lesebücher zum Vorbild solcher Schulbücher sowohl für die unteren als auch für die oberen Klassen in Österreich, das die nachfolgenden geprägt hat. Mozarts Deutsches Lesebuch für die unteren Klassen der Gymnasien - wie wir richtig voraussetzten - enthält eine Menge von antiken Themen, beginnend mit den Äsopischen Fabeln und schließend mit den historischen Nacherzählungen sowohl der griechischen als auch der römischen Schriftsteller in deutscher Übersetzung. Für unser Thema ist besonders die Tatsache von Bedeutung, dass hier gleich dreifach das Schicksal Pompejis und der Gegend

60 Auch hierbei sollten Texte gewählt werden, die „auf ihr [der Kinder, J. K.] Gemüth und ihren Charakter einen veredelnden Einfluss" ausüben (Entwurf 1849: 128).

${ }^{61}$ Ganz am Anfang stehen natürlich die deutschen Lesebücher der klassischen Sprachen.

62 Mikolášková (2012: 90) hat ermittelt, dass im J. 1854 Mozarts Anthologien die einzigen approbierten für den Deutschunterricht waren (mit Hinweis auf Erlass des h. Ministeriums für Cultus und Unterricht: Verzeichnis 1854). 
unter dem Vesuv den Schülern geschildert wird: einmal nach Plinius' Briefen an Tacitus, dann von dem Kunsthistoriker und Archäologiegründer Johann Joachim Winckelmann und zum dritten Mal als Gedicht aus der Feder von Friedrich Schiller. ${ }^{63}$ Damit bekamen die etwa zwölfjährigen Kinder nicht nur den Inhalt des Themas vorgeführt, sondern konnten auch die unterschiedlichen Formen der Bearbeitung des Themas mit dem Lehrer besprechen, was natürlich dem Zwecke eines Lesebuches inne liegt. Eigentlich finde ich es ziemlich schwierig für dieses Alter einen Fachtext zu verstehen, wie denjenigen von Winckelmann. Desto mehr könnte es überraschend wirken, dass in dem Deutschen Lesebuch für die oberen Klassen der Gymnasien, das auf den ersten Blick viel höhere Ansprüche auch auf dem Gebiet der Literaturtheorie für die Jugend stellt, von dem Thema Vesuv nur ein zeitgenössisches Stimmungsgedicht (August von Platen von Hallermünde, Der Vesuv im December aus dem J. 1830), in dem das Ereignis des Jahres 79 n. Chr. gar nicht vorkommt, dargeboten wird. ${ }^{64}$ Es sei jedoch bemerkt, dass im Ganzen die Naturszenerien in unterschiedlichen Jahreszeiten zu einem der fünf Themen Mozarts Anthologien gehören ${ }^{65}$ und dass auch hier sonst die Antike nicht ganz zu kurz gekommen ist, und die Studierenden hier u.a. sowohl antike Autoren in Übersetzung als auch wissenschaftliche oder künstlerische Passagen über das Altertum vorfanden.

Im J. 1866 lobt ein anonymer Verf. eines kurzen Beitrages in der tschechischen Zeitschrift Tábor ${ }^{66}$ die Aktivitäten des Verlegers I. L. Kober dafür, dass er Lehrbücher für tschechische Schulen herausgibt, darunter auch Deutsches Lesebuch für die zweite Gymnasialklasse von dem Mittelschullehrer Karel Antonín Madiera (Maděra), dessen erstes Lesebuch für die erste Gymnasialklasse sehr gut aufgenommen worden sei. Das Lob ist ja nicht nur deswegen, dass die Anthologie in vielen Hinsichten gut ist, sondern besonders deshalb, weil sie als erste von dieser Gattung für diejenigen Lernenden bestimmt ist, derer Muttersprache Tschechisch ist. ${ }^{67}$ Abgesehen jedoch davon, wer in dem habsburgischen Imperium das Schulbuch verfasste, musste er die Forderungen erfüllen, die der Entwurf (1849) stellte. Unsere Analyse betrifft aus diesem Blickwinkel nur die Forderung der Belebung der geschichtlichen Schulauslegung des Lehrenden und die Schilderung in Geschichtslehrbüchern.

Tschechische Lesebücher. Wie oben gesagt, waren die tschechischen Lesebücher durch die deutsche Lesebücherbildung geprägt. ${ }^{68}$ In der beobachteten Zeit haben die deutschen Werke deshalb einen grundlegenden Einfluss auf die literarische Wahrneh-

63 Mozart (1850: 263-268, Nr. 187 [„Der Ausbruch des Vesuv im ersten Jahrh. nach Ch. G.“]; 272-274, Nr. 191 [„Die Zerstörung von Herkulanum, Pompeji und Stabiä“]; 275, Nr. 192 [„„Pompeji und Herkulanum“]). Schillers Gedicht erschien dann wiederholt in Mozart (1855: 287-288) und wurde auch von anderen Verfassern in die Lesebücher eingereiht.

64 Mozart (1863: 388-389).

65 Vgl. Mikolášková (2012: 50).

66 Anonym (1866).

67 Vgl. Mikolášková (2012: 66). Sie weist darauf hin, dass Madieras Anthologien mit denen von Mozart und auch Pfannerer in vielen Hinsichten vergleichbar sind. In allen kann man alle drei Hauptkomponente vorfinden: die ästhetische, erzieherische und belehrende.

68 Vgl. Mikolášková (2012: 37), die zu den ersten die Böhmischen Lesebücher für die untersten/ mittleren/oberen Classen an Gymnasien und anderen Lehranstalten, sowie für den Privatgebrauch von František Čupr nennt; so auch Čeňková (2011: 15-24), die ihre Monographie den tschechischen Lesebüchern widmet. Pompeji in den Lesebüchern steht aber nicht im Blickwinkel dieser Autorinnen. 
mung der tschechischen Gymnasiasten gehabt, und dies nicht nur in der Form, sondern auch in dem Inhalt der einzelnen Beiträge in den literarischen Anthologien (indem mitunter auch Werke deutscher Schriftsteller und Dichter ins Tschechische übersetzt wurden). Die tschechischen Lesebücher sollten jedoch darüber hinaus Beweise dafür bringen, dass die tschechische Sprache mächtig ist, alle Literaturgattungen nicht nur auf hohem Niveau zu übersetzen, sondern auch zu schaffen. Auf den Unterschied in den deutschen Anthologien für die Deutschen auf der einen Seite und für die Tschechen auf der anderen weist Mikolášková (2012: 84) hin. Dies zählt jedoch nicht zu den Fragen, die in dem vorliegenden Beitrag erörtert werden sollten.

Hier geht es um das Bild der Kulturgeschichte mit dem Blick auf Pompeji. Und in dieser Hinsicht sind beide Sorten sehr ähnlich. Die erste Erwähnung über die Katastrophe, die der Vesuv in dem naheliegenden Gebiet verursacht hat, haben die Kinder gleich in der ersten Gymnasialklasse zu lesen bekommen, und zwar in dem tschechischen Werk von Josef Jireček. ${ }^{69}$ Der Verfasser, Abt Pavel Frey, reiste nach dem Vatikan und hat einen Ausflug zum Golf von Neapel unternommen. Und eben dieses mit eigenen Augen gesehene Gebiet beschreibt er anschaulich als einen Reisebericht, der spannend geschrieben ist, denn eben bei der Besteigung des Berggipfels lässt der Vulkan von sich spüren. Die Explosion wird sehr lebhaft geschildert, so dass die Kinder es gespannt lesen konnten, es wird hier jedoch nichts über den Ausbruch des Jahres 79 und über das Los von Pompeji, Herkulaneum u.s.w. gesagt. Mehr hätte man erfahren können, hätte man Freys Buch in die Hand genommen. Aber trotzdem: der erste Satz beginnt mit den Worten: „Während ich durch Pompeji bummelte ...". Hoffentlich hat also der Lehrer den etwa zehnjährigen Kindern entsprechend ihrem Alter von der unglücklichen Stadt etwas erzählt! Ein Jahr nach dem Erscheinen der Schulanthologie für die erste Klasse hat Jireček eine solche für die dritte Klasse derselben Mittelschulen herausgegeben. ${ }^{70}$ In der dritten Klasse des Untergymnasiums konnten die schon etwas reiferen Studenten die Beschreibung des Vesuvausbruches von dem Augenzeugen, Plinius dem Jüngeren, in der tschechischen Übersetzung lesen: zwei Briefe von Plinius an Tacitus wurden hier abgedruckt. ${ }^{71}$ Der Übersetzer wurde mit den Initialen J. J. signiert, was zu der Vermutung führte, es handelte sich um die führende Persönlichkeit der tschechischen nationalen Wiedergeburt, Josef Jungmann. Nach der gründlichen Analyse konnte ich jedoch beweisen, dass es die Anfangsbuchstaben des Herausgebers selbst, Josef Jireček, waren. ${ }^{72}$ Ähnlich wie die deutschen Lesebücher von Josef Mozart, wurden die tschechischen Schulanthologien von Josef Jireček zum Prototyp diesen Genres und die späteren Autoren haben sich von ihm inspirieren lassen. Plinius kam jedoch in den tschechischen Lesebüchern nie wieder zum Wort. Ab 1911 konnten die Lehrer damit rechnen, dass dieser antike Schriftsteller mit

69 Jireček (1856: 191-193). In demselben Buch (Jireček 1856: 126) befindet sich aus der Antike noch ein Beitrag über die römischen Katakomben von Pavel Frey. Josef Jireček hat als Mitglied einer Kommission die wissenschaftliche Terminologie für tschechische Mittelschulen, Gymnasien und Realschulen standardisiert. Seine Lesebücher und literarische Anthologien wurden von 1853 bis 1861 in den Schulen verteilt. Als Sekretär übernahm er 1859 die Leitung der Mittelschulen in Tschechien und wegen seiner sprachlichen Qualifikation auch in anderen slawischen Ländern Österreich-Ungarns sowie in Ungarn und Italien.

70 Jireček (1857).

71 Jireček 1857: 34-37, Nr. 24 („Smrt’ staršího Plinia“ [Der Tod von Plinius dem Älteren]); 50-52, Nr. 33 („Výbuch Vesuva“ [Vesuvausbruch]).

72 Kepartová (2007b: 724-732). 
seiner Vesuvausbruchschilderung im Gegenstand Latein von den Schülern gelesen wurde (s. oben). Indessen finden wir in den tschechischen Lesebüchern in der Malá slovesnost pro vy̌̌ši třídy [Kleine Literatur für höhere Klassen] von Jan Kosina und František Bartoš ab der dritten Auflage ${ }^{73}$ die Wiedergabe des Bildungsfeuilletons von dem Journalist und nationalen Schriftsteller Jan Neruda Mrtvé město [Die tote Stadt], zum ersten Mal publiziert in den Národní listy [National-Blätter] im J. 1872. ${ }^{74}$ Die Studenten lasen diesen Abschnitt in der 5. Klasse, wie darüber der zukünftige Mittelschullehrer und klassische Philologe Ladislav Brtnický berichtet. ${ }^{75}$ Die Schilderung des tschechischen Schriftstellers hat sich bewährt und so finden wir auch in dem dritten Abschnitt des Lesebuches von Václav Petrů zum ersten Male im J. $1886^{76}$ zu diesem Thema einen Beitrag des Reisenden Naturwissenschaftlers Josef Kořenský mit demselben Namen, der sich schon fest in dem Bewusstsein der Leser eingebürgert hatte. Kořenský ist öfters in den Lesebüchern vertreten und so überrascht es nicht, dass wir ihn auch in dem Lesebuch für die zweite Klasse der Mittelschulen von František Bartoš seit ihrer fünften Auflage im J. 1896 vorfinden (Z Neapole na Vesuv [Aus Neapel auf den Vesuv] a Pochovaná města [Die begrabenen Städte]). ${ }^{77}$

\section{Werke für den Gegenstand Zeichnen}

Nach dem Entwurf (1849: $\$ 21)$ ist der Gegenstand Zeichnen unter den freien Fächern eingeordnet; als Grund wird angegeben, dass es an Zeichenlehrer fehlt, ${ }^{78}$ und dass man nicht wisse, wie viele Studenten an diesem Fach (wie auch an der Kalligraphie, dem Gesang und der Gymnastik) interessiert sein würden. Die Lehrpläne für die freien Gegenstände waren dem Landes-Schulrat zur Genehmigung vorzulegen (Entwurf 1849: Anhang, \$50).

Eine andere Sache gibt es mit den Realschulen: in dem Entwurf (1849: 233, § 16) liest man auch über das Ziel eines solchen Unterrichtes: „Gewandtheit im freien Handzeichnen in gewerblicher Richtung, mit Anwendung von Tusche und Farben. Linear- und Ornamenten-Zeichnen, als Vorbereitung für Bau- und Maschinenzeichnen. Situationszeichnen in seinen ersten Elementen zum Verständniss von Situationsplänen. “ Es ist also etwas anderes, als das humanistische Zeichnen, von dem Langl (1909: 4) spricht (s. unten).

Der Zeichenunterricht kommt bei der Kunstgeschichteauslegung an der Antike, und auch an Pompeji, keinesfalls vorbei, ohne eingehend über die Kunst der Alten zu lehren. Das wussten am besten die Zeichenlehrer, die besonders nach der Weltausstellung in Paris 1900 von dem Wiener Ministerium verlangten, dass auch sie Reisestipendien

\footnotetext{
Kosina, Bartoš (1883).

Nerudas Feuilleton bleibt dann ein ständiger Bestandteil tschechischer Lesebücher.

Brtnický (1904).

76 Petrů (1886: 212-214, Nr. 134).

77 Bartoš (1896: Nr. 115-117). Nr. 116 ist ein Gedicht von Josef Wenzig, in dem mehrere Berge sprechen, darunter auch der Vesuv.

78 Die Situation hat sich binnen einem halben Jahrhundert geändert, denn in der Petition der Zeichenlehrer an das Wiener Ministerium wird darauf hingewiesen, dass viele Absolventen der Kunstakademien als Lehrer an Mittelschulen enden.
} 
bekämen, um die antiken Kunstwerke und Sehenswürdigkeiten mit eigenen Augen sehen zu können: „Wenn ein klassischer Philologe oder Historiker aus eigener Anschauung die Denkmäler altertümlicher Kunst der Römer und der Hellenen kennenlernen will, um seine Auslegungen den Schülern verständlicher zu machen, um so mehr ist es wünschenswert für einen Zeichenlehrer. Wenn ein Philologe oder ein Historiker nur in seinen Vorlesungen gelegentlich über die Baudenkmäler der Kulturnationen spricht, macht dies der Zeichenlehrer ab der 3. Klasse fast ununterbrochen, denn seine Worte ergänzen nur das, was graphisch verwirklicht wird. Es ist also ersichtlich, dass der Zeichenunterricht im ständigen Berühren mit der Kunst ist." Die Zeichenlehrer haben es erreicht; auch sie verfügten also über das Reisestipendium nach dem Süden, wie vor ihnen schon die klassischen Philologen und Geographie- und Geschichtslehrer seit $1893 .{ }^{79}$ Ein obligatorisches Ziel der Stipendienreisen war mitunter auch Pompeji und das Museum von Neapel mit seinen vielen Kunststücken und anderen Funden aus dem Gebiet am Golf von Neapel. Seit dem Ende des 19. Jh. kommen hierher nämlich schon Scharen nicht nur der Europäer, sondern auch der Amerikaner, die das alltägliche Leben der alten Römer näher und anschaulich kennenlernen wollen.

Der österreichische Realschule-Kunstlehrer, Maler, Bildhauer und Erzähler Josef Langl hat in der Funktion des Regierungsrates in dem Schulprogramm der I. Realschule in Wien für das Schuljahr 1908/1909 über die Entwicklung des Gegenstandes berichtet und auf „die Spaltung des humanistischen und gewerblichen Zeichnens“ hingewiesen. Seit den neunziger Jahren des 19. Jh. wurde das Historische in den Hintergrund gestellt und der Kunstunterricht und seine Methoden wurde sehr oft zum Thema verschiedener Literatur, Tagungen und Kongressen, und dies im internationalen Maßstab. „Die österreichischen Zeichenlehrer dürfen sich rühmen, nicht nur den regsten Anteil an diesem Gärungsprozeß, sondern zugleich bestimmenden Einfluß auf die allmähliche Klärung der Verhältnisse im allgemeinen Kunstunterricht genommen zu haben“, heißt es weiter. Wie spiegelt sich diese Situation in dem wirklichen Unterricht an den österreichischen Mittelschulen wider? Mit der Gründung der Realschulen löst sich der Mittelschulzeichenunterricht von dem der Volksschule ab und der humanistische Unterricht als Kunstfach trennt sich von dem gewerblichen praxisnahen langsam definitiv ab. Das Freihandzeichnen wurde sehr unterstützt. Künstlerisches Zeichnen drang in die österreichischen Schulen aus Paris ein, es war auch Frankreich, wo die Lithographie den größten Einfluss auf die Kunsterziehung ausübte (Langl 1909: 11). In Österreich hat man nach Gipsmodellen gezeichnet, die besonders der Radierer L. Schön für die Schulen als Hilfsmittel gestaltete. Die geschulten Zeichenlehrer unterlagen den strengen Prüfungen an den Kunstakademien, die sie absolvieren mussten.

Seit der Gründung der Realgymnasien wurde auch hier das Zeichnen als obligat eingeführt. Durch diese Einrichtung kam dann der Zeichenunterricht auch in das klassische Gymnasium (Langl 1909: 13). Seit der Schulreform in 1870 hat sich die Realschule dem Gymnasium sehr angepasst und wurde zur allgemeinen Bildungsanstalt. Das 1868 in Wien gegründete Museum für Kunst und Industrie, dem sich eine Kunstschule anschloss, hatte zur Folge, dass von hier alle Schulen historische Vorlagen für den Zeichenunterricht bekamen. Es wurden Holz- und Gipsmodelle an die Schulen verschickt,

79 NA ČR, Fond MKV/R, 26D: Zeichenreisestipendien. Näher Kepartová (2007a: 130-131). 


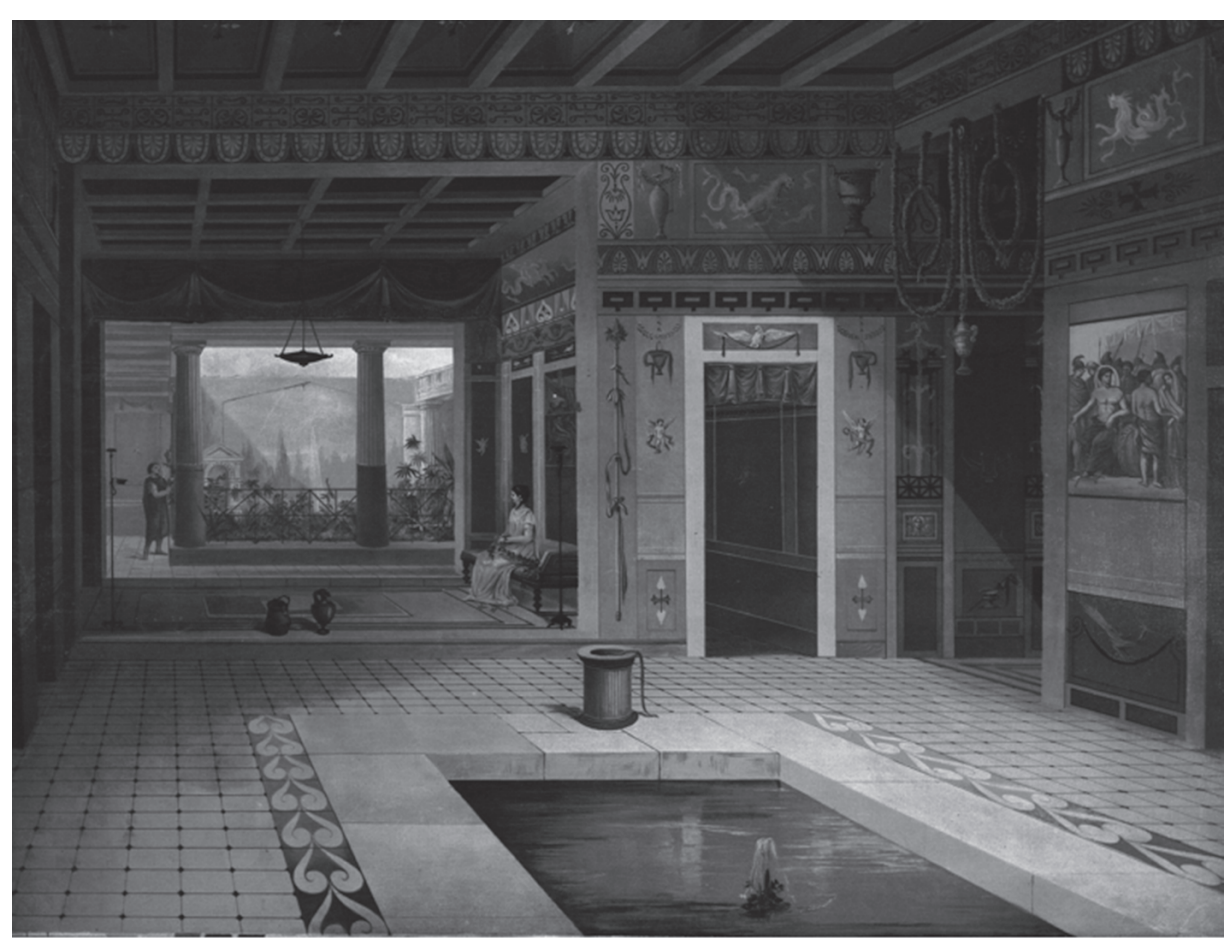

Langl, Josef. Denkmäler der Kunst. Bilder zur Geschichte vorzugsweise für Mittelschulen und verwandte Lehranstalten. Wien: Eduard Hölzel, 1872: Haus des tragischen Dichters

(Tschechische Nationalbibliothek, Sign. 11 B 1243, Nr. 9321).

die aber (nicht nur) Langl (1909: 14-15) kritisiert, weil sie nicht frei waren, der Lehrende hatte viel an die Tafel zeichnen müssen und die Schüler hatten sie nachzumachen - ein trockener Unterricht, den ich mit dem grammatischen Drill in den klassischen Sprachen vergleichen könnte. Alles wurde bis zum letzten Detail in den Instruktionen und in dem Lehrplan beschrieben. Auch die Modelle mussten approbiert werden. Es waren auch Vorschläge gefallen, Kunstgeschichte als solche in das Curriculum der Mittelschulen einzubringen, aber erfolglos. Den Geschichts- und Sprachenlehrern wurde nur empfohlen, an geeigneten Stellen „künstlerische Exkurse“ zu machen. Man sollte auch Wandbilder nutzen. „Prof. E. Hanak versuchte zur Zeit zum ersten Mal, kleine kunstgeschichtliche Abbildungen in sein Lehrbuch der Geschichte aufzunehmen, und seiner Anregung folgte der Schreiber [Langl, J. K.] dieses für das Realgymnasium im II. Bezirk, an welchem wir damals beide Lehrkollegen waren, einen Zyklus von Wandbildern der Baudenkmale des Altertums zu malen“ (Langl 1909: 18). Bis 1909 erschienen 75 Blätter von Langl, unter ihnen Die Thermen von Caracalla in Rom sowie das pompejanische Haus des tragischen Dichters (das in der Tschechischen Nationalbibliothek vorhanden ist). Seitdem schmückten die Wände der Schulkabinette, -gänge usw. historische Bilder. Der inspirierende Zeichenunterricht blieb unverändert auch nach 1892, als für alle österreichischen Länder Fachinspektoren bestellt waren; damals haben die Lehrer auf Besseres gehofft, vergebens. Sie hatten sich an die bestehenden Normen zu halten (Langl 1909: 21)! Erst 1899 (an 
Realschulen) und 1900 (an Gymnasien) durfte man sich in größerem Umfang auch dem Naturzeichnen widmen, wobei „das pädagogische Moment der ästhetisch-künstlerischer Erziehung" nicht ausfallen durfte (Langl 1909: 22). Das alte approbierte Lehrmittelverzeichnis für den Zeichenunterricht wurde „ad acta gelegt“. Damit wurden auch die antiken Gips-, Holz- und eventuell Korkmodelle überflüssig. Die Schülerwerke hatten auf der ersten Ausstellung des Naturzeichnens an den Mittelschulen einen großen Erfolg und das wurde dann auch im Brünner Museum gezeigt. Im April 1909 erschien in dem Verordnungsblatt ein neuer Lehrplan für das Freihandzeichnen an allen Mittelschulen und damit entfielen die Abgüsse definitiv.

Schulbücher für den Kunstunterricht. Ein Schulwerk verdient in diesem Zusammenhang besonders genannt zu werden, denn es enthält sehr viel Pompeji. Sein Verfasser ist der oben zitierte Absolvent der Wiener Akademie der bildenden Künste, der österreichische Realschule-Zeichenlehrer Josef Langl, der im ersten Band die Kunst des Altertumes einschließlich der Griechen vorstellte und in dem zweiten Band sich den Römern widmete. ${ }^{80}$ In den Kunstbeilagen und Plänen finden die Leser u.a. sechs Tafeln mit Bildern aus Pompeji (Plan der Stadt, das Forum triangulare, das Forum civile, die kleineren Thermen, Plan des Hauses des tragischen Dichters sowie die Gräberstraße und ein Plan des „Normalhauses“, das jedoch kaum in Pompeji zu finden ist), darüber hinaus noch die Stadt Pompeji mit dem Forum sowie nochmals das Haus des tragischen Poeten. Pompeji wird hier als „Ergänzung und in vielen Beziehungen als Commentar zu den Denkmälern Roms" verstanden. Aus der Wahl der Bilder geht hervor, dass Architektur bevorzugt wird und das Alltagsleben beiseite geblieben ist. Langl lehnt sich an die wichtigsten Werke seiner Zeit von Overbeck, Gell, Mazois, Nissen u.a. Im Vorwort heißt es, er wolle mit seinen „Blättern auf dem Gebiete des Kunst- und kunstwissenschaftlichen Unterrichtes in den mittleren Schulen wieder ein Schritt vorwärts" tun (im Sinne der reformierenden Tendenzen österreichischen Bildungswesens). Im Kap. IV. liest der Schüler einen Text (Langl 1876: 78-128), der ihn über die einzelnen Phasen der römischen Kunstentwicklung in Pompeji belehrt. Aber auch über die Geschichte der durch die Fügung des Schicksals betroffenen Stadt sollen die Lernenden einen Abriss nach den antiken Quellen bekommen, sowie eine kurze ziemlich trockene Übersicht über die Ausgrabungen und eine detaillierte Beschreibung des urbanistischen Ausbaus und einzelner Bauten Pompejis, wobei er solche Details anführt, wie z.B. dass „Lucius Crassus verwendete schon Säulen aus fremdem Marmor in seinem Hause, Marcus Scaurus hatte das Atrium seines Hauses mit monolithen schwarzen Marmorsäulen von 38 Fuss Höhe geschmückt (Langl 1876: 105) usw. Langls Buch konnte die Jugend anspornen, auch Bulwers Letzte Tage von Pompeji ${ }^{81}$ zu lesen, ein Werk, das er mehrmals zitiert. Wohl deshalb hat er auch das Haus des tragischen Dichters, d.h. das Haus des Glaucus aus Bulwers Roman, und Plan sowie die Stiche von William Gell zur Beschreibung gewählt. Das Buch hätte problemlos als

80 Langl (1876).

81 Mit dem Autor des Romans teilt er die Meinung mit, dass zur Zeit des Vesuvausbruches die Bevölkerung sich im Amphitheater vergnügte. Bulwers Roman wurde schon im 19. Jh. in viele Sprachen übersetzt und auch für Kinder umgearbeitet: in deutscher Sprache Bulwer-Lytton, Körber (1848), Bulwer-Lytton, Nieritz (1850); Bulwer-Lytton, Höcker (1889), Bulwer-Lytton, Moritz (1892), in tschechischer Sprache Bulwer-Lytton, Malý (1877). 
Reiseführer gelten können. Als Kunstlehrer konnte jedoch Langl das „Kunstbezogenes“ nicht unbeachtet lassen. Und so kommt er endlich zu dem eigentlichen Thema (Langl 1876: 116): „Wir haben nun die Stadt in ihren baulichen Überresten durchwandert und es erübrigt sich nur noch, in kurzen Zügen die artistische Werthschaft derselben zu schildern und einige Punkte in Betreff des Technischen zu erörtern. "Im Vergleich zu der vorgestellten Passage, die auf fast 40 Seiten hinkommt, nimmt der künstlerische Abschnitt nur zehn Seiten. Wichtig jedoch ist, dass Langl die Bedeutung der Pompejifunde für das Kunststudium trotz des Provinzialniveaus zu schätzen weiß, wenn er schreibt (Langl 1876: 118): „Dennoch aber bleibt uns Pompeji in seinen Kunstproductionen wichtig und hochinteressant, da diese uns in ästhetisch-artistischer Hinsicht ein Schlüssel zum Verständnis der antiken Kunstanschauung sind und in technischer Beziehung nach den verschiedensten Richtungen hin die einzige Auskunft geben."

Langls Auslegungen in seinen Bildern zur Geschichte fand der Gymnasiallehrer Josef Novák als nicht ausreichend und hat deshalb im Schulprogramm des Gymnasiums in Jindřichův Hradec (Neuhaus) 1884 einen Nachtrag mit Nutzung von bekannten Werken wie z.B. von dem oben genannten František Velišský (1876 sowie seine Reiseberichte), Johannes Overbeck und vieler anderen (mitunter auch von den Tschechen Josef Wünsch und Miroslav Tyrš), und mit den Zeichnungen von seinen Schülern nachgeliefert. Es handelte sich um Grundrisse, Hauptansichten, aber besonders bilderbezogene ausführlichere Texte. Novák (1884: 21-26) bietet einen Abschnitt über Pompeji, der ersichtlich durch Wünschs Pompeji und die Pompejaner beeinflusst ist, d.h. viel interessanter als die trockene Schilderung von Langl. Diese Texte sollten unter den Wandbildern von Langl in den Schulgängen gehängt werden. Auch er beschreibt das Haus des tragischen Dichters. Am wichtigsten kann jedoch erscheinen, dass der Text auf Tschechisch geschrieben ist und der Verfasser zur Anschauung Beispiele aus den böhmischen Ländern heranzieht, wie z.B. den Kreuzgang im Krankenhaus beim Heiligen Johannes und im Franziskanerkloster (Novák 1884: 24). Auf diese Weise wollte er den Kunstgeschichtsstoff den Lernenden anschaulicher machen. Er führt auch ein Verzeichnis der Architektur und ihrer Teile nach verschiedenen Kriterien und auch Fragen zur Wiederholung des Lehrstoffes Pompeji miteingeschlossen - an.

Letzten Endes erfuhren die Schüler der habsburgischen Mittelschulen in den böhmischen Kronländern die meisten Informationen über Pompeji in dem zuerst freien Gegenstand Zeichnen, dies jedoch erst seit dem letzten Viertel des 19. Jh.

\section{Schluss}

Aus der Analyse der Lehr- und Lesebücher, also des Schulbuchkomplexes mit den übrigen Unterrichtsmaterialien (Wandtafeln, Atlanten usw.) des gegebenen Zeitraumes 1849-1918 geht hervor, dass Pompeji als eine Materialgrube für das Verständnis des Alltagslebens im römischen Reich zuerst nur mangelhaft herangezogen wurde. In den Lateinlehrbüchern ging es ja in erster Linie um die Grammatik und die wurde an Beispielen aus der obligatorischen Lektüre der klassischen Autoren genommen, deren Verzeichnis in dem Entwurf (1849) festgelegt wurde. Zu diesen für den Schulgebrauch vorbereiteten Passagen in den Lesebüchern gab es mit der Zeit auch Kompendien, die 
den Schülern helfen sollten, den antiken Text zu entziffern. Antike Autoren, die über das Schicksal Pompejis geschrieben haben, waren lange nicht dabei. Erst seit 1911 wurde Plinius der Jüngere in den Lehrplan der Schullektüre an den österreichischen Mittelschulen eingeordnet. Pompejanische Inschriften wurden - natürlich mitunter auch wegen des Vulgärlateins und des erotischen Inhalts mancher Graffiti - kaum berücksichtigt, mit der tschechischen Übersetzung zuerst im Jahre 1913 in der Bildungszeitschrift Osvěta. ${ }^{82}$ Wohl der erste Beleg aus dem lateinischen Lesebuch stammt aus dem J. 1920;83 allerdings wurden die inschriftlichen Texte allgemein lange dem Unterricht entzogen. ${ }^{84}$

Nicht anders ging es in den Lehrbüchern für den Gegenstand Geschichte. Pompejis Untergang wurde im besseren Fall erwähnt, oft jedoch gar nicht reflektiert. Man hat dies auf die Schul- und Hauslektüre der Jugend in dem Gegenstand Deutsche Sprache und Tschechische Sprache übertragen. Sowohl in den deutschen als auch in den tschechischen Lesebüchern finden wir also Beschreibungen in unterschiedlichen Formen - als Brief des Augenzeugen (Plinius), als einen wissenschaftlichen Beitrag (Winckelmann), als ein romantisches Gedicht (Schiller, Platen), als einen Reisebericht (Pavel Frey, Kořenský), erzieherisches Feuilleton (Neruda) usw. Ausdrücklich für die Gymnasiasten ist das Buch von Josef Pražák, Die tote Stadt Pompeji bestimmt, das 1903 erschien, obwohl sie schon seit fast einem Viertel Jahrhundert das viel amüsantere Büchlein von Josef Wünsch in den Schulbibliotheken zur Verfügung hatten. Zeichnungen pompejanischer Funde und der Stadt an sich fanden wohl zuerst in das Lehrbuch von Gindely Eingang. Dies ist jedoch nicht nur auf die Missbilligung zurückzuführen, sondern eher auf die technischen Schwierigkeiten und die hohen Kosten. Es war auch sonst unüblich, Illustrationen den Schulbüchern beizugeben.

Die Lehrer haben im J. 1900 ein Instrument in die Hand bekommen, das ihnen die Situation erleichtern konnte. Josef Kubik hat nämlich ein Kompendium für die Lehrerschaft nicht nur der klassischen Sprachen, sondern auch der lebendigen Sprachen (bes. des Deutschen) geschaffen. ${ }^{85}$ Hier finden die Lehrkräfte zuerst das Verzeichnis der griechischen und römischen, aber auch deutschen Schulautoren mit genauen Angaben zu Werken und konkreten Stellen vorgelegt, bei welchen sie das pompejanische Material mit Gewinn nutzen können. Er geht dabei von den zu der Zeit in den österreichischen Schulen in Gebrauch üblichen Lesebüchern aus. ${ }^{86}$ Kubik gibt zu, dass der Lehrer selten dazu kommt, „den Schülern über Pompeji etwas mitzutheilen. Und doch sollte man es nicht versäumen, dieses, ich möchte sagen, lebendige Zeugnis antiken Lebens bei der Lectüre besonders der alten Schriftsteller heranzuziehen. "87 Darüber hinaus ist sich Kubik des-

82 Vysoký (1913).

83 Heřmanský (1920: 246-247): sechs Inschriften. Heřmanskýs lateinische Lehr- und Lesebücher wurden noch nach dem zweiten Weltkrieg herausgegeben.

84 Ein selbständiges Bändchen der lateinischen Inschriften für den Schulgebrauch hat Brtnický (1909: 6-31) zusammengestellt und den Lehrern im Jahresbericht seines Gymnasiums vorgelegt. Über die mögliche Heranziehung von griechischen und römischen Inschriften in ganz konkreten Beispielen in den philologischen und historischen Stunden wurde schon früher geschrieben: Simon (1897); Pompeji ist nicht dabei.

85 Kubik (1900).

${ }^{86}$ Er führt diejenigen von L. Lampel (für verschiedene Klassen österreichischer Mittelschulen) sowie dem Autorenpaar K. F. Kummer und K. Stejskal (auch mehrere Lesebücher für verschiedene Klassen österreichischer Mittelschulen) an.

87 Kubik (1900: 2). 
sen bewusst, dass „In der Regel aber verlassen unsere Schüler das Gymnasium, ohne über diese alle gebildeten Stände interessierende Frage etwas zu erfahren." Mit seinem dünnen Werk von insgesamt 59 Seiten hat er also den Lehrern eine große Hilfe gegeben, denn sein Ziel war es: „,vor allem wird man auf Pompeji da hinweisen, wo die Stelle selbst zu ihrer Erklärung einen Hinweis auf diese oder jene Seite antiken Lebens verlangt, über welche uns die ausgegrabene Stadt mit den in derselben gemachten Funden Aufschluss gibt, oder wo sie uns gleichsam einen greifbaren Beweis liefert für diese oder jene Eigenthümlichkeit oder Einrichtung im alltäglichen Leben der Alten. "88 Auf der einen Seite wird Pompeji mit Rom verglichen, die Lehrenden sollen jedoch die Schüler darauf aufmerksam machen, das Pompeji nur eine kleine Stadt war. Auf der anderen Seite sollen die Lernenden auch die konkrete, vom Vesuv verschüttete Stadt kennenlernen - wir sind ja schon in der Zeit, als man mehr verreiste und die Jugendlichen sollten auf diese Weise auf den Pompejibesuch vorbereitet werden. Allerdings ist es schon die Zeit, in der man auch im Unterricht neue Medien zur Belebung der Auslegung benutzte. Ein Jahr vor Kubiks Handbüchlein hat Franz Prix (1899) zu Pompeji Begleitworte zu einer Reihe von Projectionsbildern (mit Skioptikon) herausgegeben. Um die Jahrhundertwende gab es schon reichliches Hilfsmaterial für die Lehrer, so dass sie - mit gutem Willen - den Mittelschulfrequentanten genügende Informationen zum anschaulichen Erlernen sowie zum Nachdenken vorlegen konnten. Über die hohe Gelehrsamkeit der Vortragenden ist nicht zu zweifeln. Sie haben es in den Tausenden von Schulprogrammen, ${ }^{89}$ die die Bildungsanstalten nicht nur innerhalb von dem habsburgischen Imperium, sondern auch mit den deutschsprachigen Ländern austauschten, und anderswo (in Zeitschriften und eigenen Monographien) hinlänglich bewiesen.

Nun entsteht die wichtigste Frage: wie konnte der Lehrer im Unterricht Zeit finden, dies alles zu nutzen? Wie die Erinnerungen mancher Studenten (Josef Václav Frič, Svatopluk Čech, Svatopluk Machar, Fritz Mauthner, Karel Václav Rais, Alois Jirásek, Josef Svátek u.a.) zeigen, waren nicht nur die meisten Lehrenden, sondern auch die meisten Auszubildenden an den österreichischen Mittelschulen (wohl nicht nur) in den böhmischen Ländern und in der von uns untersuchten Zeit an der Bildung wenig interessiert. ${ }^{90}$ Die Schuld für das Elend des österreichischen Unterrichts sieht Svatopluk Machar ${ }^{91}$ sowie Fritz Mauthner ${ }^{92}$ nicht an den Lehrenden, sondern an dem System, das die Lehrer und ihre Auslegungen mit den vielen Regeln und Paragraphen, mit viel Pedanterie zu sehr eingeschnürt hat, sie gelähmt hat und in den Schülern nur das kritiklose Nachsagen

88 Kubik (1900: 2).

89 Aus der Produktion der Schulprogramme, die unser Thema berühren, können ausser den schon oben erwähnten z.B. folgende zitiert werden: Kastner (1873: passim), Stütz (1911); Gaheis (1912: Pompeji passim; 1913: 20; 1914: 17-18, 24), Potuček (1907: 3-5). Sonst z.B. Kvapil (1893: 41, 46, 274-285, 300; mit dem eigenen Namen Bohuslav Záborský): Das Buch enthält sowohl die politische als auch die Kulturgeschichte Roms. Die benutzten Illustrationen - Rekonstruktionen nach den erhaltenen Denkmäler - stammen oft aus Pompeji, ohne dass dies gesagt wird; das war in dieser Zeit üblich. Nur der zweite Band hat über 400 Seiten und war deshalb in dem Unterricht nicht brauchbar. Ein Verzeichnis der ausgewählten Arbeiten über Pompeji in tschechischer Sprache s. Kepartová (2007a: 217-226).

90 Natürlich gab es auch unter den Lateinlehrern Ausnahmen; vgl. Jirásek (1980: 186), der den Prof. Končinský am Gymnasium in Königsgraz lobt.

91 Machar (1984: 223).

92 Mauthner (1918: 88). 
und Nachahmen unterstützte. So lag es an den Lernenden selbst, ob sie den Willen hatten, die besten Lebensjahre der Selbstbildung zu widmen. Ein solcher Schüler/Student hat auch die Wege gefunden, zu wertvollen Werken und Zeitschriften (Lumír, Osvěta, Květy und vor allem Světozor) heranzukommen. Die Pflicht jeder Mittelschule war es, eine Schulbibliothek zu haben; in einer Bücherei oder aber auf einem Flohmarkt haben auch manche Jungen sich Bücher besorgt und mit den Kommilitonen ausgetauscht. ${ }^{93}$

\section{BIBLIOGRAPHIE 94}

\section{Archivalische Quellen}

Nationalarchiv, Prag, Fond MKV/R, 26D: Zeichenreisestipendien.

\section{Literatur}

Alberti, E., 1872. Marcus Charinus, der junge Christ in Pompeji. Eine Erzählung aus dem Römischen Alterthum für die Jugend. Leipzig: Teubner.

Anonym, 1866. „Učebné knihy pro české školy“ [Lehrbücher für tschechische Schulen]. Tábor 2/38, nicht paginiert.

Anonym, 1918. „České Pompeje“ [Das böhmische Pompeji]. Kopřivy. List satirický 10/3, 5.

Bartoš, F., 1896. Česká čítanka pro druhou třídu škol středních [Tschechisches Lesebuch für die zweite Klasse der Mittelschulen]. 5., völlig umbearbeitete Aufl. Brno: K. Winiker.

Becker, W. A., 1838-1840. Gallus oder römische Scenen aus der Zeit Augusts. Zur Erläuterung der wesentlichsten Gegenstände aus dem häuslichen Leben der Römer. Leipzig: Freidrich Fleischer.

Berger, T., 2007. „Böhmisch oder Tschechisch? Der Streit über die adäquate Benennung der Landessprache der böhmischen Länder zu Anfang des 20. Jahrhunderts“. In: M. Nekula, I. Fleischmann, A. Greule (Hrsg.), Franz Kafka im sprachnationalen Kontext seiner Zeit: Sprache und nationale Identität in öffentlichen Institutionen der böhmischen Länder. Wien / Köln / Weimar: Böhlau, 167-182.

Bojesen, E. F., Hoffa, J., 1841. Handbuch der römischen Antiquitäten nebst einer kurzen römischen Literaturgeschichte von E. F. Bojesen. Zum Gebrauch für Gymnasien und Schulen aus dem Dänischen übersetzt von J. Hoffa. Giesen: G. F. Heyer.

Borgongino, M., Stefani, G., 2001-2002. „Intorno alla data dell'eruzione del 79 dopo d. C.“. Rivista di Studi Pompeiani 12-13, 177-215.

Brtnický, L., 1904. [Rez. zu Pražák (1903)]. Listy filologické 31, 49-50.

Brtnický, L., 1909. „Starořímské nápisy náhrobni“ [Altrömische Sepulkralinschriften]. In: Výroční zpráva c. k. vyššího gymnasia v Hradci Králové za rok 1908/9 [Jahresbericht des k. k. Obergymnasiums in Königsgraz für das Jahr 1908/9]. Hradec Králové: Bratřri Peřinové, 6-31.

Brtnický, L., 1912. „Plinius mladší, nový autor školní na našich gymnasiích“ [Plinius der Jüngere, ein neuer Schulautor an unseren Gymnasien]. Nová doba 19, 822-833.

Bulwer-Lytton, E., Höcker, O., 1889. Die letzten Tage von Pompeji. Kulturhistorische Erzählung aus dem Jahr 79 nach Chr. 3. Aufl. Berlin: Warschauer.

Bulwer-Lytton, E., Körber, Ph. W., 1848. Diomedes und Clodius. Erzählung aus den letzten Tagen von Pompeji. Nürnberg: Lotzbeck.

Bulwer-Lytton, E., Malý, J., 1877. Poslední dnové Pompej [Die letzten Tage von Pompeji]. Praha: Mourek. Bulwer-Lytton, E., Moritz, P., 1892. Die letzten Tage von Pompeji: eine Erzählung für die Jugend. Stuttgart: Thienemanns Verlag.

Bulwer-Lytton, E., Nieritz, G., 1850. Pompeji's letzte Tage [= Jugend-Bibliothek Jg. 11, Bd. 4]. Berlin: Simion.

93 Machar (1984: 229-230), Mauthner (1918: 94), Jirásek (1980: 159-160 u. anderswo) u.a.

94 Bei den Lehr- und Lesebüchern führe ich nur diejenige Auflage an, die ich zur Ansicht bekommen habe. 
Čapek, J., 1910. „Některé listy Pliniovy“ [Einige Briefe von Plinius]. In: Výroční zpráva c. k. státního reálného a vyššího gymnasia v Klatovech vydaná za školní rok 1909-1910 [Jahresbericht des k. k. Staatsrealu. Obergymnasiums in Klattau]. Klatovy: Selbstverlag des Gymnasiums, 9-15.

Čeňková, J., 2011. Česká čitanka pro starši školní věk v letech 1870-1970 a její kanonické texty [Das tschechische Lesebuch für das ältere Schulalter in den Jahren 1870-1970 und seine kanonischen Texte]. Praha: Karolinum.

Entwurf, 1849. Entwurf der Organisation der Gymnasien und Realschulen in Oesterreich. Vom Ministerium des Cultus und Unterrichts. Wien: Kaiserlich-königliche Hof- und Staatsdruckerei.

Fritsch, A., 1976. „Sprache und Inhalt lateinischer Lehrbuchtexte. Ein unterrichtsgeschichtlicher Rückblick“. In: W. Heistermann (Hrsg.), Abhandlungen aus der Pädagogischen Hochschule Berlin. Band III. Fachdidaktik und fächerübergreifender Unterricht. Berlin: Colloquium Verlag, 116-169.

Funke, C. Ph. et al., 1800-1805. Neues Real-Schullexicon enthaltend die zur Erklärung der alten Klassiker nothwendigen Hülfswissenschaften, vornämlich Geographie, Geschichte, Philosophie, Alterthümer und Mythologie. Erster Theil-Fünfter Theil. Braunschweig: Schulbuchhandlung.

Gaheis, A., 1912. „Altrömisches Leben aus den Inschriften. I. Teil“. In: XII. Jahresbericht des $k$. $k$. Staatsgymnasiums im XIII. Bezirke. Wien: Selbstverlag des Gymnasiums, 5-26.

Gaheis, A., 1913. „Altrömisches Leben aus den Inschriften. I. Teil“. In: XIII. Jahresbericht des $k$. $k$. Staatsgymnasiums im XIII. Bezirke. Wien: Selbstverlag des Gymnasiums, 4-31.

Gaheis, A., 1914. „Altrömisches Leben aus den Inschriften. I. Teil“. In: XIV. Jahresbericht des $k$. $k$. Staatsgymnasiums im XIII. Bezirke. Wien: Selbstverlag des Gymnasiums, 5-28.

Gindely, A., 1868. Lehrbuch der allgemeinen Geschichte für Ober-Gymnasien. Erster Band. 2., durchgehends verbesserte Auflage mit 165 Abbildungen. Prag: Tempsky.

Gindely, A., Erben, J., 1872. Dějepis všeobecný. Pro střední školy české. Svazek první. Věk starý [Allgemeine Geschichte. Für die tschechischen Mittelschulen. Band I. Alte Zeit]. Übers. von J. Erben. Praha: Tempský.

Gindely, A., Jireček, K. J., 1877. Dějepis všeobecný pro vyšši tř́idy škol středních. Díl I. Věk starý [Allgemeine Geschichte für die höheren Klassen der Mittelschulen. Band I. Alte Zeit]. Übers. und bearb. von K. J. Jireček. 2., umgearbeitete Aufl. Praha: Tempský.

Gindely, A., Kovář, M., 1877. Dějepis všeobecný pro vy̌š̌i tř́idy škol středních. Věk starý [Allgemeine Geschichte für die höheren Klassen der Mittelschulen. Alte Zeit]. Übers. von M. Kovář. Praha: Tempský.

Gindely, A., Řehák, J. J., 1884. Dějepis všeobecný pro nižší třídy škol středních. Svazek první. Věk starý [Allgemeine Geschichte für die unteren Klassen der Mittelschulen. Erster Band. Alte Zeit]. Übers. von J. J. Ǩehák. Praha: Tempský.

Grube, A. W., 1852. Charakterbilder aus der Geschichte und Sage für einen propädeutischen Unterricht. Band 1: Die vorchristliche Zeit. Leipzig: Friedrich Brandstetter

Guhl, E., Koner, W., 1860. Das Leben der Griechen und Römer nach antiken Bildwerken dargestellt. Griechen. Berlin: Weidmannsche Buchhandlung.

Guhl, E., Koner, W., 1861. Das Leben der Griechen und Römer nach antiken Bildwerken dargestellt. Römer. Berlin: Weidmannsche Buchhandlung.

Hales, S., Paul, J. (Hrsg.), 2011. Pompeii in the Public Imagination from Its Rediscovery to Today. Oxford: Oxford University Press.

Harrisson, S., 2011. „Bulwer-Lytton’s The Last Days of Pompeii: Re-creating the City“. In: Hales, Paul (2011: 75-89).

Heřmanský, F., 1920. Latinská čitanka pro 3. a 4. třídu středních škol. Část 1. Text [Lateinisches Lesebuch für die 3. und 4. Klasse der Mittelschulen. Teil 1. Der Text]. Praha: Jednota českých filologů.

Hohler, E. Th., 1822. Abbildungen Römischer und Griechischer Alterthümer nach Antiken für die Studierende und Freunde der Alterthumskunde. Wien / Krems: B. Ph. Bauer.

Honl, I., 1967. „Antické prvky v českém místopise“ [Antike Elemente in der bömischen Topographie]. Zprávy Jednoty klasických filologů 9, 20-22.

Jacobmeyer, W., 2011. Das deutsche Schulgeschichtsbuch 1700-1945. Die erste Epoche seiner Gattungsgeschichte im Spiegel der Vorworte. Band I-Band III. Berlin [u.a.]: Lit.

Jahres-Bericht, 1855. Jahres-Bericht über das k. k. akademische Gymnasium zu Olmütz währed des SchulJahres 1855. Olmütz: F. Slavik.

Jahresbericht, 1857. Jahresbericht des k. k. Gymnasiums zu Pilsen für das Schuljahr 1856-1857. Pilsen: J. M. Schmid. 
Jirásek, A., 1980. Z mých pamètí [Aus meinen Erinnerungen]. 7. Aufl. Praha: Mladá fronta.

Jireček, J., 1856. Čítanka pro první třídu nižšího gymnasia [Lesebuch für die erste Klasse des Untergymnasiums]. Praha: Nákladem kněhoskladu Calvova.

Jireček, J., 1857. Čítanka pro třetí třídu nižšího gymnasia [Lesebuch für die dritte Klasse des Untergymnasiums]. Praha: Nákladem kněhoskladu Calvova.

Kameníček, F., Dvořák, R., 1902. Všeobecný dějepis pro vy̌šš třídy škol středních. 2., verkürzte und bearbeitete Aufl. Praha: J. Otto.

Kastner, E., 1873. „O zř́zzení domů starořímských“ [Über den Aufbau von altrömischen Häusern]. In: Výroční zpráva o cís. král. českém gymnasiu realním v Praze [Jahresbericht über das k. k. tschechische Realgymnasium zu Prag]. Praha: Selbstverlag des Gymnasiums, 1-14.

Kepartová, J., 2000. „Milota Zdirad Polák a Pompei“. Rivista di studi Pompeiani 11, 153-159.

Kepartová, J., 2001. „Pompeje očima Josefa Pražáka“ [Pompeji mit den Augen von Josef Pražák]. Marginalia historica 4, 225-243.

Kepartová, J., 2007a. Češi v Pompejích 1748-1948. Kulturněhistorická studie [Die Tschechen in Pompeji 1748-1948. Kulturhistorische Studie]. Praha: Univerzita Karlova, Pedagogická fakulta.

Kepartová, J., 2007b. „Přeložil Josef Jungmann Pliniovy dopisy?“ [Hat Josef Jungmann Plinius’ Briefe übersetzt?]. Česká literatura 5, 724-732.

Kepartová, J., 2014. „Středoškolská antika ve třetí čtvrtině 19. stoleti““ [Die Gymnasialantike im dritten Viertel des 19. Jahrhunderts]. Historica Olomucensia 47, 91-116.

Kepartová, J., 2016. „Druhý život prvního císaře v románu 19. stoleti“‘ [Das Nachleben des ersten Kaisers im Roman des 19. Jahrhunderts]. Bibliotheca Alexandrina 3, 80-90.

Klinghardt, J., 1896. Die Berücksichtigung der bildenden Kunst beim Unterrichte in der Geschichte und Erdkunde in den mittleren Klassen des Gymnasiums. I. Theil [= Neunundachtzigste Nachricht von dem Herzoglichen Friedrichs-Gymnasium zu Altenburg. Beilage]. Altenburg: Oskar Bonde.

Klinghardt, J., 1897. Die Berücksichtigung der bildenden Kunst beim Unterrichte in der Geschichte und Erdkunde in den mittleren Klassen des Gymnasiums. II. Theil [= Neunzigste Nachricht von dem Herzoglichen Friedrichs-Gymnasium zu Altenburg. Beilage]. Altenburg: Oskar Bonde.

[Kolář, M.], 1865. „Noviny z českého Herkulanum““ [Zeitung aus dem böhmischen Herkulanum]. Tábor $1 / 41$, nicht paginiert.

[Kolář, M.], 1866. „Český Vesuv“ [Der böhmische Vesuv]. Tábor 2/36, nicht paginiert.

Kosina, J., Bartoš, J., 1883. Malá Slovesnost', kterou za knihu učebnou a čítací pro vy̌šsi tř́dy škol středních sestavili J. Kosina a F. Bartoš [Kleine Literatur, die als das Lehr- und Lesebuch für die oberen Klassen der Mittelschulen J. Kosina und F. Bartoš zusammenstellten]. 3. Aufl. Brno: Winiker.

Kubik, J., 1900. Pompeji im Gymnasialunterricht. Wien: Hölder.

Kvapil, A., 1893. Řím. Počátky, vzrůst a pád veleřiše římské. Svazek II. Světovláda a pád [Rom. Anfänge, Aufstieg und Niedergang des römischen Großreiches. Band II. Die Weltherrschaft und Niedergang]. Praha: Kober.

Langl, J., 1872a. Denkmäler der Kunst. Bilder zur Geschichte vorzugsweise für Mittelschulen und verwandte Lehranstalten. Wien: Eduard Hölzel.

Langl, J., 1872b. Denkmäler der Kunst. Bilder zur Geschichte vorzugsweise für Mittelschulen und vewandte Lehranstalten. Text-Beilage mit Holzschitten zum ersten Cyclus: Das Alterthum. Wien: Eduard Hölzel.

Langl, J., 1876. Denkmäler der Kunst. Bilder zur Geschichte vorzugsweise für Mittelschulen und vewandte Lehranstalten. Textbeilage mit Lichtdruckbildern, Karten, Plänen etc. zum zweiten Cyklus: Das Alterthum. (Die Kunst bei den Römern.). Wien: Eduard Hölzel.

Langl, J., 1909. „Sechzig Jahre österreichisches Zeichenunterrichts“. In: Achtunddreißigster Jahresbericht der k. k. I. Staatsrealschule im II. Bezirke in Wien für das Schuljahr 1908/1909. Wien: Selbstverlag der Schule, 3-28.

Lemercier, N.-L., 1847. Poslední dnové města Pompeji. Přiběh ze života starých Ǩimanů, ve francouském jazyku sepsaný od Lemerciera [Die letzten Tage der Stadt Pompeji. Erzählung aus dem Leben der alten Römer, auf Französisch von Lemercier]. Übers. von K. W. Püner. Praha: Jar. Pospišil.

Machar, J. S., 1984. Konfese literáta [Bekenntnisse eines Literaten]. 5. Aufl. Praha: Československý spisovatel [geschrieben in den Jahren 1900-1901].

Mauthner, F., 1918. Erinnerugen. I. Prager Jugendjahre. München: Georg Müller. 
Mikolášková, M., 2012. Formování obrazu literatury na středních školách českých zemí v 19. století: Na podkladu analýzy německých gymnaziálních čitanek z let 1849-1918 [Formung des Literaturbildes an den Mittelschulen der böhmischen Länder im 19. Jhdt.: Auf Grundlage der Analyse der deutschen Gymnasiallesebücher aus den Jahren 1849-1918]. Dissertation. České Budějovice: Jihočeská univerzita, Filozofická fakulta, Ústav bohemistiky.

Moormann, E. M., 2011. „Christians and Jews at Pompeii in Late Nineteenth-Century Fiction“. In: Hales, Paul (2011: 171-184).

Mozart, J., 1850. Deutsches Lesebuch für die unteren Klassen der Gymnasien. Zweiter Band. Wien: Verlag Carl Gerold.

Mozart, J., 1855. Deutsches Lesebuch für die oberen Classen der Gymnasien. Zweiter Band. 2., umgearbeitete Aufl. Wien: Carl Gerold's Sohn.

Mozart, J., 1863. Deutsches Lesebuch für die oberen Klassen der Gymnasien. Dritter Band. 3. umgearbeite Aufl. Wien: Carl Gerolds Sohn.

Nieritz, G., 1865. Záhuba města Pompejí čili Bázeň Boží a důvěra v Boha: povídka z prvních dob křestanských pro mládež její [Untergang der Stadt Pompeji: also Gottesfurcht und Glaube an Gott: Erzählung aus den ersten christlichen Zeiten für ihre Jugend]. Übers. von J. Pečírka. Praha: Styblo.

Novák, J., 1884. „Výklad Langlových obrazů k dějinám“ [Erklärung der Bilder zur Geschichte von Langl]. In: Výroční zpráva c. k. gymnasia v Jindřichově Hradci za školní rok 1884 [Jahresbericht des k. k. Gymnasiums in Neuhaus für das Schuljahr 1884]. Jinřichův Hradec: Selbstverlag der Schule, 3-30.

Novotný, F., 1936. Hynek Vysoký. Praha: Česká akademie věd a umění.

Pacovský, A., 1816. „Zřícení dvou překrásných měst: Herkulanum a Pompeji. Z Plinia mladšího“ [Die Vernichtung zweier wunderschönen Städte: Herkulanum und Pompeji. Aus Plinius dem Jüngeren]. Prvotiny pěkných umèní neb literní př́lohy $k$ c. $k$. Vídeňským novinám pro národ český a slovenský na rok 1816 20. Juni 1816, Nr. 50, 393-394.

Petrbok, V., 2007. „Der Unterricht aus deutscher Literatur an tschechischen Gymnasien und aus tschechischer Literatur an deutschen Gymnasien von 1850 bis 1914 anhand einer Analyse der Lesebücher". Brücken. Germanistisches Jahrbuch Tschechien - Slowakei N. F. 15, 249-278.

Petrů, V., 1886. Čítanka pro nižši třídy stredních škol. Část III. [Lesebuch für die unteren Klassen der Mittelschulen. III. Band]. Praha: I. L. Kober.

Potuček, A., 1907. „Von klassischen Stätten“. In: Jahresbericht des k. k. Kaiser Franz Joseph-Staats-Gymnasiums in Aussig. Aussig: Selbstverlag des Gymnasiums, 3-28.

Pražák, J., 1903. Mrtvé město Pompeje [Die tote Stadt Pompeji]. Praha: Beaufort.

Prix, F., 1899. Pompeji. Begleitworte zu einer Reihe von Projectionsbildern. Sonderdruck aus Jahresbericht des Theresianischen Gymnasiums. Wien: Theresianum.

Pütz, W., 1833. Grundriss der Geographie und Geschichte der Staaten des Alterthums: für die oberen Klassen eines Gymnasiums. Köln: Renard u. Dübyen.

Pütz, W., 1850. Grundriss der Geographie und Geschichte der alten, mittleren und neuen Zeit für die mittleren Klassen der Gymnasien und für höhere Bürgerschulen. Erste Abtheilung: Das Alterthum. 6., verbesserte Auflage. Koblenz: Carl Bädeker.

Rothenburg, K.-H. von, 2009. Geschichte und Funktion von Abbildungen in lateinischen Lehrbüchern - ein Beitrag zur Geschichte des textbezogenen Bildes. Frankfurt am Main: Peter Lang.

Schinnagl, M., 1853. Lateinisches Lesebuch für die zweite Gymnasial-Klasse: Als Vorübung zur Lectüre des Cornelius Nepos nach Putsches lateinischer Grammatik. 2., verbesserte Aufl. Wien: Fr. Beck.

Schuch, Ch. Th., 1842. Privatalterthümer, oder wissenschaftliches, religiöses und häusliches Leben der Römer. Ein Lehr- und Handbuch für Studierende und Alterthumsfreunde. Karlsruhe: Ch. Th. Groos.

Sedláček, J., 1911. Výbor z listi̊ Plinia Mladšího. Pro gymnasia a reálná gymnasia [Auswahl aus den Briefen des Plinius dem Jüngeren. Für Gymnasien und Realgymnasien]. Praha: Česká grafická a. s. „Unie“.

Simon, J., 1897. „Epigraphik im Dienste des Gymnasialunterrichtes“. Zeitschrift für die österreichischen Gymnasien 48, 1128-1133.

Sobek, F., 1900. Dějiny všeobecné pro nižší třídy škol středních. Díl I. Věk starý [Allgemeine Geschichte für die unteren Klassen der Mittelschulen. Band I. Alte Zeit]. 5., fast unveränderte Aufl. Praha: L. Kober.

Stefan, K., 1868. Rukovět římských starožitností se stručnou historií římské literatury. Dle spisu dra. E. F. Bojesena a dra J. Hoffy [Leitfaden der römischen Alterthümer mit der kurzen Geschichte der römischen Literatur. Nach der Schrift von E. F. Bojesen und Dr. J. Hoffa]. Praha: Edvard Grégr. 
Stefani, G., Borgongino, M., 2007. „Das Datum des Vesuvausbruchs“. In: J.-P. Petit, G. Santoro (Hrsg.), Leben im römischen Europa. Von Pompeji nach Bliesbruck-Reinheim. Paris: Errance, 43-45.

Stejskal, J., 1913. Vzpomínky z cesty po Italii (Benátky, Řím, Neapol, Pompeje) [Erinnerungen aus der Italienreise (Venedig, Rom, Neapel, Pompeji)]. Roudnice: nákladem vlastním.

Stütz, M., 1911. „Ein Gang durch Pompei“. In: XIII. Jahresbericht des Kaiser-Franz Josef-Staatsrealgymnasiums in Gablonz a. N. Gablonz a. N.: Selbstverlag der Schule, 1-12.

Svatoš, M., 1994. „Výuka antickým jazykům a literaturám v době Lannových gymnaziálních studii““ [Der Unterricht der antiken Sprachen und Literaturen in der Zeit der Gymnasialstudien von Adalbert Lanna]. In: J. Šubrt (Hrsg.), Villa Lanna - Antika a Praha 1872. Praha: KLP, 28-36.

Šafránek, J., 1918. Školy české: obraz z jejich vývoje a osudi̊. II. svazek. R. 1848-1913 [Tschechische Schulen: das Bild aus deren Entwicklung und Schicksale. II. Band. Die J. 1848-1913]. Praha: Matice česká.

Velišský, F., 1876. Život Řekưv a Římanův [Das Leben der Griechen und Römer]. Praha: vlastním nákladem (za podpory Matice české a Jednoty českých filologů).

Verzeichnis, 1854. „Verzeichnis der an den Gymnasien Österreichs zulässigen deutschen Lehr- und Hilfsbücher für Schüler“. Zeitschrift für die österreichischen Gymnasien 5, 567-571.

Vysoký, H., 1913. „Pompejské nápisy“ [Pompejanische Inschriften]. Osvěta 43, 583-592 und 647-654.

Wünsch, J., 1880. Pompeje a Pompejané. Ze vlastní zkušenosti a dle spisů nejlepších [Pompeji und die Pompejaner. Aus eigener Erfahrung und nach den besten Werken]. Praha: J. Otto.

\title{
BEILAGE
}

Langl, Josef. Denkmäler der Kunst. Bilder zur Geschichte vorzugsweise für Mittelschulen und verwandte Lehranstalten. Wien: Eduard Hölzel, 1872: Haus des tragischen Dichters (Tschechische Nationalbibliothek, Sign. 11 B 1243, Nr. 9321).

\section{OBRAZ POMPEJÍ VE VÝUCE V ZEMÍCH KORUNY ČESKÉ. DOBA HABSBURSKÉHO ŠKOLSTVÍ (1849-1918)}

Pompeje a jejich zánik dlouho nebyly tematizovány ani v hodinách klasických jazyků, ani v jiných předmětech. Učebnice dějepisu se většinou omezovaly na konstatování, že Pompeje byly zničeny za vlády císaře Tita; více se o osudu Pompejí mohly děti poučit z německých a českých školních čítanek. Tyto čítanky dlouho nebyly ilustrovány. První obrázky z Pompejí můžeme nalézt v dějepisných učebnicích Gindelyho. Plánky a obrázky nacházeli studenti v učebnicích kreslení a na zdech školních chodeb. Mohli též nahlédnout do školních kompendií, která jim byla k dispozici v žákovských školních knihovnách.

\author{
Jana Kepartová \\ Karlsuniversität, Prag \\ jana.kepartova@pedf.cuni.cz
}

